\title{
Retrieval of vertical constituents and temperature profiles from passive submillimeter wave limb observations of the Martian atmosphere: a feasibility study
}

\author{
Joachim Urban, Karin Dassas, François Forget, and Philippe Ricaud
}

\begin{abstract}
The investigation of the Martian atmosphere is of key importance for an understanding of the planets present and past. Passive limb observations of thermal radiation at submillimeter wavelengths in the 320-350-GHz range by use of a state-of-the-art satellite receiver on a low Mars orbit allow important parameters such as the mixing ratios of $\mathrm{H}_{2} \mathrm{O}, \mathrm{HDO},{ }^{12} \mathrm{CO},{ }^{13} \mathrm{CO}, \mathrm{O}_{3}$, and $\mathrm{H}_{2} \mathrm{O}_{2}$ as well as the thermal profile to be retrieved with high precision and unprecedented vertical range and resolution, providing valuable information for better understanding of the planet's water cycle, atmospheric dynamics, and photochemistry. The feasibility of these kinds of measurement is demonstrated by means of model simulations based on realistic atmospheric, spectroscopic, and instrumental parameters. Temperature can be retrieved to $\sim 90 \mathrm{~km}$ with half-scale height vertical resolution from single-scan measurements of emission lines of the long-lived species ${ }^{12} \mathrm{CO}$ and ${ }^{13} \mathrm{CO}$. The global water-vapor distribution can be measured even under dry or wet conditions with good vertical resolution from the surface to $\sim 45 \mathrm{~km}$, and simultaneous observations of $\mathrm{HDO}$ allow useful information on the $\mathrm{D} / \mathrm{H}$ ratio up to an altitude of $\sim 30 \mathrm{~km}$ to be derived. The sensitivity of the limb-sounding technique also permits information on the photo-chemically important minor species $\mathrm{O}_{3}$ and $\mathrm{H}_{2} \mathrm{O}_{2}$ to be obtained. It is shown that spectral averaging may improve precision, altitude range, and resolution of the retrieved profiles. Other frequency bands are explored, and the $435-465-\mathrm{GHz}$ range is suggested as a possible alternative to the $320-350-\mathrm{GHz}$ range.
\end{abstract}

\section{Introduction}

\section{A. Motivation}

The motivations for an investigation of the Martian atmosphere are numerous. Playing a central role in the evolution of the planet, its study is crucial for a better understanding of the present and past of

When this research was performed, J. Urban (jo.urban@ rss.chalmers.se) and P. Ricaud were with the Observatoire Aquitain des Sciences de l'Univers, 2, Rue de l'Observatoire, B.P. 89, 33270 Floirac, France. J. Urban is now with the Department of Radio and Space Science, Chalmers University of Technology, 41296 Göteborg, Sweden and P. Ricaud is with the Laboratoire d'Aérologie, 14, Avenue Edouard Belin, 31400 Toulouse, France. K. Dassas and F. Forget are with the Laboratoire de Météorologie Dynamique, Université Paris 6, 4, place Jussieu, B.P. 99, 75252 Paris Cedex 05, France. K. Dassas is now at Institut d'Astrophysique Spatiale, Université Paris XI, France. planet Mars. The current Martian climate system is a complex combination of atmospheric dynamics coupled with dust, $\mathrm{CO}_{2}$, and water cycles. Understanding how this system works is a key to the history of the planet and its evolution. Because of the similarities between Earth and Mars, a systematic comparative study of the Martian atmosphere's meteorology, climatology, and aeronomy should furthermore tell us much about the evolution of our own planet.

Observational data are needed to constrain chemical and dynamical models, which are major tools nowadays available for the study of the Martian atmosphere and climate system. ${ }^{1-3}$ Global observations of temperature and wind fields are required for a complete view of the atmospheric circulation. Water vapor and related isotopic species are parameters to be studied for a better understanding of the seasonally asymmetric water cycle, characterized by seasonal and possibly diurnal exchange cycles with the surface. Finally, with photolysis extending to the ground owing to the planet's low surface pressure, photochemical cycles that control the abundances of major $\left(\mathrm{CO}_{2}, 95 \%, \mathrm{~N}_{2}, 3 \%\right)$ and minor 
$\left(\mathrm{CO}, 0.08 \%, \mathrm{H}_{2} \mathrm{O}, 0.01 \%, \mathrm{O}_{2}, 0.1 \%\right)$ constituents play a major role in the Martian atmosphere and need to be investigated by measurements of key species. ${ }^{4-7}$

Several space missions have so far contributed to the study of key parameters for atmospheric dynamics. Temperature, determined by meteorological and radiative processes, is the major parameter that controls physical (e.g., condensation) and chemical processes. Most-recent measurements of infrared spectrometers such as the Thermal Emission Spectrometer (TES) of the Mars Global Surveyor ${ }^{8}$ (MGS) mission provided global profile information at moderate vertical resolution larger than one scale height. ${ }^{9-12}$ Winds have never been directly measured by spaceborne sensors but are indirectly derived from the thermal gradients. ${ }^{12}$ Some sparse observational information on winds has also been obtained from Earth-based radio observations of Doppler shifts. ${ }^{13}$ The water cycle has so far been studied only by measurements of the water-vapor column, e.g., from TES nadir infrared measurements ${ }^{14}$ or Earth-based telescopes. ${ }^{15,16}$ Present missions such as Mars Express, ${ }^{17}$ which started its observations in January 2003, are designed to extend and improve on TES measurements to better characterize the dynamics and photochemical cycles of the Martian atmosphere. Vertically well-resolved temperature and ozone profiles are measured by UV solar and stellar occultation, ${ }^{18}$ with the disadvantage of the limited global and temporal coverage of this technique. Columns of ozone from UV nadir sounding during daytime as well as columns of water vapor from IR spectroscopy will also become available, ${ }^{19}$ and in addition some information on the column abundances of HDO and $\mathrm{CO}$ should be obtained. In the near future, NASA will launch the Mars Reconnaissance Orbiter ${ }^{20}$ carrying the Mars Climate Sounder, which is designed for limb observations of temperature, aerosol, and watervapor profiles employing filter radiometry at thermal IR wavelengths.

\section{B. Submillimeter-Wave Radiometry}

In this study we investigate the potential of spaceborne heterodyne spectroscopy at submillimeter wavelengths for the exploration of the Martian atmosphere. Compared to other spectroscopic techniques such as UV, visible, and thermal IR, microwave temperature and constituent retrievals have certain advantages. Intense emission lines exist for major molecules of the Martian atmosphere, and accurate profiles can be obtained for extreme meteorological conditions and during day and night. Radiative transfer at millimeter and submillimeter wavelengths $(\lambda>500 \mu \mathrm{m})$ is relatively insensitive to aerosols, ${ }^{21,22}$ given the long wavelengths compared with the typical dimensions reported for dust and cloud particles in the Martian atmosphere $\left(r_{\text {eff }}<4 \mu \mathrm{m}\right){ }^{23,24}$ Thus information can be retrieved under conditions with heavy aerosol loading, which means during periods of particular scientific interest (dust storms, cloud formation). Spectroscopy of rotational lines in the vibrational ground state is relatively simple and, in particular, the local thermal equilibrium (LTE) assumption remains valid for rotational lines to above $120 \mathrm{~km}$ (non-LTE processes are a major problem for temperature retrievals in the IR above $\sim 50 \mathrm{~km}){ }^{25}$ Moreover, reliable space-proven (all solid state) superheterodyne receiver technology is nowadays available up to $\sim 700 \mathrm{GHz}$, and latest digital spectrometer technology allows the narrow lines emitted at the very low pressures of the upper Martian atmosphere to be resolved. ${ }^{26-28}$

$\mathrm{H}_{2} \mathrm{O}$ and $\mathrm{HDO}$ are the key target species for the study of the diurnal and seasonal water cycles and the isotopic fractionation. $\mathrm{D} / \mathrm{H}$ ratios that are five to six times that on Earth have been reported,29,30 which might be caused by mechanisms that favor the escape to space of $\mathrm{H}$ rather than $\mathrm{D}$. Seasonal and diurnal condensation and fractionation cycles involving approximately half of the available atmospheric water vapor, with HDO being more concentrated in its icy phase because of its lower vapor pressure, may also play a controlling role for the atmospheric water vapor abundance and may lead to considerable seasonal variations. ${ }^{16,31,32} \mathrm{CO}$ is a long-lived species whose variations ${ }^{33}$ can be used to trace slow meridional transport processes, in addition to direct observations of winds from Doppler shifts. Temperature and pressure profiles, essential parameters for atmospheric dynamics and chemistry, can be retrieved simultaneously from observations of ${ }^{12} \mathrm{CO}$ and ${ }^{13} \mathrm{CO}$ lines. Moreover, ${ }^{12} \mathrm{CO}$ and ${ }^{13} \mathrm{CO}$ as well as minor constituents such as $\mathrm{O}_{2}, \mathrm{O}_{3}$, and $\mathrm{H}_{2} \mathrm{O}_{2}$ with strong transitions in the submillimeter wavelengths range are potential targets for the study of the photochemical state of the Martian atmosphere and surface. $\mathrm{H}_{2} \mathrm{O}_{2}$, never detected on Mars, is assumed to be a key reservoir for the chemically active $\mathrm{HO}_{x}$ radicals. With the three-body recombination of $\mathrm{CO}$ and $\mathrm{O}$ being slow, the equilibrium composition of the Martian $\mathrm{CO}_{2}$ atmosphere without catalytic cycles would contain much lower mixing ratios of $\mathrm{CO}$ and $\mathrm{O}_{2}$ than observed. ${ }^{34} \mathrm{H}_{2} \mathrm{O}_{2}$ probably also acts as a sterilizing oxidant near the surface, which could also diffuse in the subsurface. ${ }^{35}$ Ozone is controlled by catalytic cycles $\left(\mathrm{HO}_{x}, \mathrm{NO}_{x}, \mathrm{O}_{x}\right)$ as in the Earth's middle atmosphere, and observations would allow the predicted variation due to significant water-vapor and temperature variations to be investigated.5,36 Measurements of other species such as radicals involved in the photochemical cycles would also be desirable but are more difficult owing to the species' low abundances or their weak spectroscopic line strengths.

In what follows, we first investigate in detail the feasibility of profile measurements of the aforementioned key target molecules $\mathrm{H}_{2} \mathrm{O}, \mathrm{HDO},{ }^{12} \mathrm{CO},{ }^{13} \mathrm{CO}$, $\mathrm{O}_{3}$, and $\mathrm{H}_{2} \mathrm{O}_{2}$ by simulating a state-of-the-art receiver on a low-altitude Mars orbit performing passive observations of thermal emission lines in the 320-350-GHz spectral range at the atmospheric limb and at nadir. This spectral range provides a compromise with respect to the line strengths of the major target lines (increasing with frequency), the sensitivity of the receiver (decreasing with frequency), and 
the field of view for a reasonably sized antenna (decreasing with frequency). The study was conducted while the state-of-the-art microwave sounder Mars Atmosphere Microwave Brightness Observer (MAMBO) was being designed. ${ }^{6}$ The instrument's general design, performance, and scientific objectives (which also include Doppler wind measurements and surface science) will be discussed elsewhere. Here we focus on the retrieval of vertical constituents and temperature profiles.

In Section 2 we describe the MOLIERE-5 model (Microwave Observation Line Estimation and Retrieval, version 5), used in this study for the simulation of spectroscopy, radiative transfer, instrument characteristics, and profile retrieval. Section 3 provides an overview of the instrument concept that we have adopted. The assumptions made for the retrieval simulations are described in detail in Section 4 , and the resultant theoretical capabilities of submillimeter wave limb sounding of the Martian atmosphere are summarized in Section 5. Alternative target line selections are discussed in Section 6, and conclusions are drawn in Section 7.

\section{Simulating Radiative Transfer and Inversion: the MOLIERE-5 Model}

Measurements of a state-of-the-art submillimeter wave limb sounder as well as constituents and temperature retrievals were simulated by use of the general forward-and-inversion model for the millimeter and submillimeter wavelengths range, MOLIERE-5. This model, validated in several intercomparison activities, ${ }^{37-39}$ was explained in detail by Urban et $a l .38$

The MOLIERE-5 forward model comprises modules for spectroscopy, radiative transfer, and instrument characteristics. Important properties of the absorption coefficient module with respect to the Martian atmosphere are its capability of line-by-line calculation as well as its inclusion of $\mathrm{H}_{2} \mathrm{O}$ and $\mathrm{CO}_{2}$ continuum models. ${ }^{40,41}$ The radiative transfer module allows for calculations in different geometries such as limb and nadir sounding from orbiting platforms. A spherically stratified (one-dimensional) emitting and absorbing atmosphere is assumed. Weighting functions, required for inversions, are calculated by differentiation of the radiative transfer equation analytically after discretization. Several independent modules allow instrument characteristics such as the antenna's field of view, the sideband response of a heterodyne receiver, and the spectrometer's bandwidth and resolution to be taken into account.

The MOLIERE-5 inversion model consists of a module that calculates linear optimal estimation, a least-squares retrieval method that uses statistical $a$ priori knowledge of the retrieved parameters for the regularization of ill-posed inversion problems. ${ }^{43}$ Both forward and inversion modules are included within a loop allowing nonlinear inversions to be calculated iteratively by use of a Levenberg-Marquardt scheme. The model computes diagnostics such as the mea- surement and smoothing error covariance matrices along with contribution and averaging kernel functions. Additional features of the inversion code are the possibility of retrieving typically unknown additional parameters such as offsets in the nominal pointing angle of a limb scan or in the assumed temperature of the ground.

\section{Instrumental Concept}

To simulate a realistic performance of a state-of-theart submillimeter-wave heterodyne receiver, we adopted the instrumental characteristics of the Mars Atmosphere Microwave Brightness Observer (MAMBO), the concept of a passive microwave sounder that was extensively studied by a consortium of research institutes and companies from France, the United States, Germany, and Sweden. ${ }^{6}$ This receiver, designed to characterize the dynamics and the composition of the Martian atmosphere by measurements at the atmospheric limb and at nadir, was optimized for observations of selected lines in the $320-350-\mathrm{GHz}$ range of the key species $\mathrm{H}_{2} \mathrm{O}(325.153 \mathrm{GHz}), \mathrm{HDO}$ $(335.396 \mathrm{GHz}),{ }^{12} \mathrm{CO}(345.796 \mathrm{GHz}),{ }^{13} \mathrm{CO}(330.588$ $\mathrm{GHz}), \mathrm{O}_{3}(326.901 \mathrm{GHz})$, and $\mathrm{H}_{2} \mathrm{O}_{2}(326.982 \mathrm{GHz})$. Key elements of the front-end design are a 230-mm-diameter main reflector with a $3-\mathrm{dB}$ beam width of $0.28^{\circ}$ at $335 \mathrm{GHz}$, corresponding to $\sim 7.6 \mathrm{~km}$ in terms of tangent altitude for a $350-\mathrm{km}$ orbit, and two planar Schottky-diode mixers that are subharmonically pumped by phase-locked Gunn local oscillators fixed tuned at 329.198 and $341.811 \mathrm{GHz}$. The downconverted signals of the double-sideband heterodyne receiver are spectrally analyzed by a combination of two state-of-the-art chirp-transform $(\Delta v$ $=100 \mathrm{kHz}$; maximum bandwidth, $200 \mathrm{MHz}$ ) and eight autocorrelator spectrometers (each with 128 channels; maximum bandwidth, $1024 \mathrm{MHz}$ ). It should be noted that the overall receiver concept was constrained to meet the stringent requirements on mass, size, power consumption, and data rate that are typical for such a mission. ${ }^{6}$ The instrumental characteristics derived represent therefore realistic assumptions for the simulations of this study.

\section{Setup for the Simulation Study}

\section{A. Simulation of Measurements}

Measurements were simulated for the individual bands by use of the forward model part of MOLIEREv5.32.

Spectroscopic line parameters for the line-by-line calculation were taken from the Verdandi database, ${ }^{43,44}$ which merges frequencies, line intensities, and lower-state energies from the Jet Propulsion Laboratory catalog 45 with pressure-broadening parameters from the HITRAN compilation. ${ }^{46}$ Moreover, broadening parameters for target lines were adapted to Martian conditions by use of measured or calculated values for $\mathrm{CO}_{2}$ broadening or, if measurements were not available, air-broadening parameters were scaled by a factor of 1.65 as estimated from the ratio of collisional broadening coefficients in air and $\mathrm{CO}_{2}$ 
Table 1. Target Lines and Back-End Spectrometer Configuration for the 320-350-GHz Range

\begin{tabular}{|c|c|c|c|c|c|c|}
\hline \multirow[b]{2}{*}{ Band } & \multirow[b]{2}{*}{ Species } & \multirow[b]{2}{*}{$\begin{array}{c}v_{0} \\
(\mathrm{GHz})\end{array}$} & \multicolumn{2}{|c|}{$\begin{array}{l}\text { Chirp Transform } \\
\text { Spectrometer }\end{array}$} & \multicolumn{2}{|c|}{ Autocorrelator Spectrometer } \\
\hline & & & $\begin{array}{l}\text { Bandwidth } \\
(\mathrm{MHz})\end{array}$ & $\begin{array}{c}\Delta v \\
(\mathrm{MHz})\end{array}$ & $\begin{array}{c}\text { Bandwidth } \\
(\mathrm{MHz})\end{array}$ & $\begin{array}{c}\Delta v \\
(\mathrm{MHz})\end{array}$ \\
\hline \multirow[t]{2}{*}{$\mathrm{A}$} & ${ }^{12} \mathrm{CO}$ & 345.796 & 200 & 0.1 & $2 \times 1024$ & 8 \\
\hline & ${ }^{13} \mathrm{CO}$ & 330.588 & $80^{a}$ & 0.1 & $1 \times 512$ & 4 \\
\hline \multirow[t]{2}{*}{$\mathrm{D}$} & $\mathrm{O}_{3}$ & 326.901 & & & $1 \times 64$ & 0.5 \\
\hline & $\mathrm{H}_{2} \mathrm{O}_{2}$ & 326.982 & & & $1 \times 256$ & 2 \\
\hline
\end{tabular}

${ }^{a}$ Shared spectrometer.

for molecules and lines already studied. ${ }^{47,48}$ Whereas this approximation was adequate for our simulations, all relevant line-broadening parameters and their temperature dependence should be accurately measured in the laboratory to allow for the analysis of actual atmospheric measurements. $\mathrm{CO}_{2}$ and $\mathrm{H}_{2} \mathrm{O}$ continuum emissions were modeled with appropriate parameterizations. .0,41 $^{-}$

The atmospheric model was adopted from a general circulation model of the Martian atmosphere ${ }^{3}$ (see plots of the profiles in Section 5). Because of the expected high variability or large uncertainty of the concentrations of target species, extreme cases (wet and dry atmospheres, upper limit conditions) were investigated additionally.

Refraction was not considered in the radiative transfer calculations because, owing to the low ground pressure (approximately 6-7 hPa), its effect is negligible. Cosmic background radiation was taken into account. When the line of sight hit the ground, the temperature of the surface was used for the background term.

The sensor model assumed a platform altitude of $350 \mathrm{~km}$, as proposed as baseline for the Mars orbiter, and a main antenna with a $230-\mathrm{mm}$ diameter leading to a 3-dB field of view of approximately $7.6 \mathrm{~km}$ at the tangent point (Mars radius, $\sim 3397 \mathrm{~km}$ ) for a frequency of $335 \mathrm{GHz}$. A continuous limb scan from 0 to $130 \mathrm{~km}$ with a constant velocity of $4 \mathrm{~km} / \mathrm{s}$ was modeled, according to the instrument specifications, leading to a widening of the effective antenna field of view. A spectrometer readout in 1-s intervals, corresponding to the acquisition of a limb measurement every $4 \mathrm{~km}$ in terms of tangent altitudes, was simulated. For nadir sounding, an integration time of $5 \mathrm{~s}$ was assumed. Local-oscillator frequencies of $329.198 \mathrm{GHz}$ (for the bands of $\mathrm{H}_{2} \mathrm{O}, \mathrm{HDO}, \mathrm{O}_{3}$, and $\mathrm{H}_{2} \mathrm{O}_{2}$ ) and $338.820 \mathrm{GHz}$ (for ${ }^{12} \mathrm{CO}$ and ${ }^{13} \mathrm{CO}$ ) and a perfect sideband ratio of 0.5 were chosen.

Simulations were performed assuming the backend design proposed for MAMBO. Each target line can be observed with a combination of two kinds of spectrometer: in total, two 200-MHz-wide chirp transform spectrometers with high spectral resolution of $100 \mathrm{kHz}$ to resolve the line centers as well as eight flexible wideband autocorrelator spectrometers, each having 128 channels and covering the line wings, were used. The back-end design adopted for the individual target bands is summarized in Table 1 . Figure 1 shows the results of radiative transfer calculations for standard atmospheric conditions.

\section{B. Retrieval Simulations}

To estimate the nominal capabilities of submillimeterwave limb sounding for the study of critical parameters of the Martian atmosphere we performed nonlinear retrieval simulations, using the MOLIERE-v5.32 inversion model.

Mixing ratio profiles of all species with lines residing in a target band were retrieved simultaneously. $\mathrm{H}_{2} \mathrm{O}$ and HDO profiles were retrieved from individual bands, whereas $\mathrm{O}_{3}$ was retrieved together with $\mathrm{H}_{2} \mathrm{O}_{2}$. Temperature was retrieved along with the mixing ratios of ${ }^{12} \mathrm{CO}$ and ${ }^{13} \mathrm{CO}$. Pressure was recalculated after each iteration from the retrieved temperature profile by use of the hydrostatic equation and a reference pressure of $7 \mathrm{hPa}$. For each band a profile of $\mathrm{CO}_{2}$ was retrieved to account for continuum emissions at low tangent altitudes. Mixing ratio profiles, temperatures, and pressures were in general calculated on the grid defined by the tangent altitudes of the measurement in 4-km altitude steps. For comparison, retrieval simulations that employed a reduced altitude grid with $10-\mathrm{km}$ resolution were also performed. To ensure realistic retrieval simulations, additional parameters such as a bias in the pointing angle of the limb scan, a typically critical but uncertain parameter of a limb sounder, and an offset in the temperature of the ground, that accounts for emissions of the Mars surface captured by the antenna at low tangent altitudes and at nadir, were retrieved simultaneously.

Nonlinear retrievals were performed, starting from a first guess (a priori), which differed from the (socalled true) scenario used to simulate the measurement. To ensure smooth convergence a Marquardt parameter of 0.1 with a change factor of 5 was used, according to the implemented algorithm ${ }^{38}$ that used the $a$ priori variances as a diagonal scaling matrix.

Measurement errors were assumed to be uncorrelated for each spectrometer channel and were estimated from the standard radiometer formula with the nominal integration time and assuming a doublesideband receiver noise temperature of $\sim 1600 \mathrm{~K}$. 

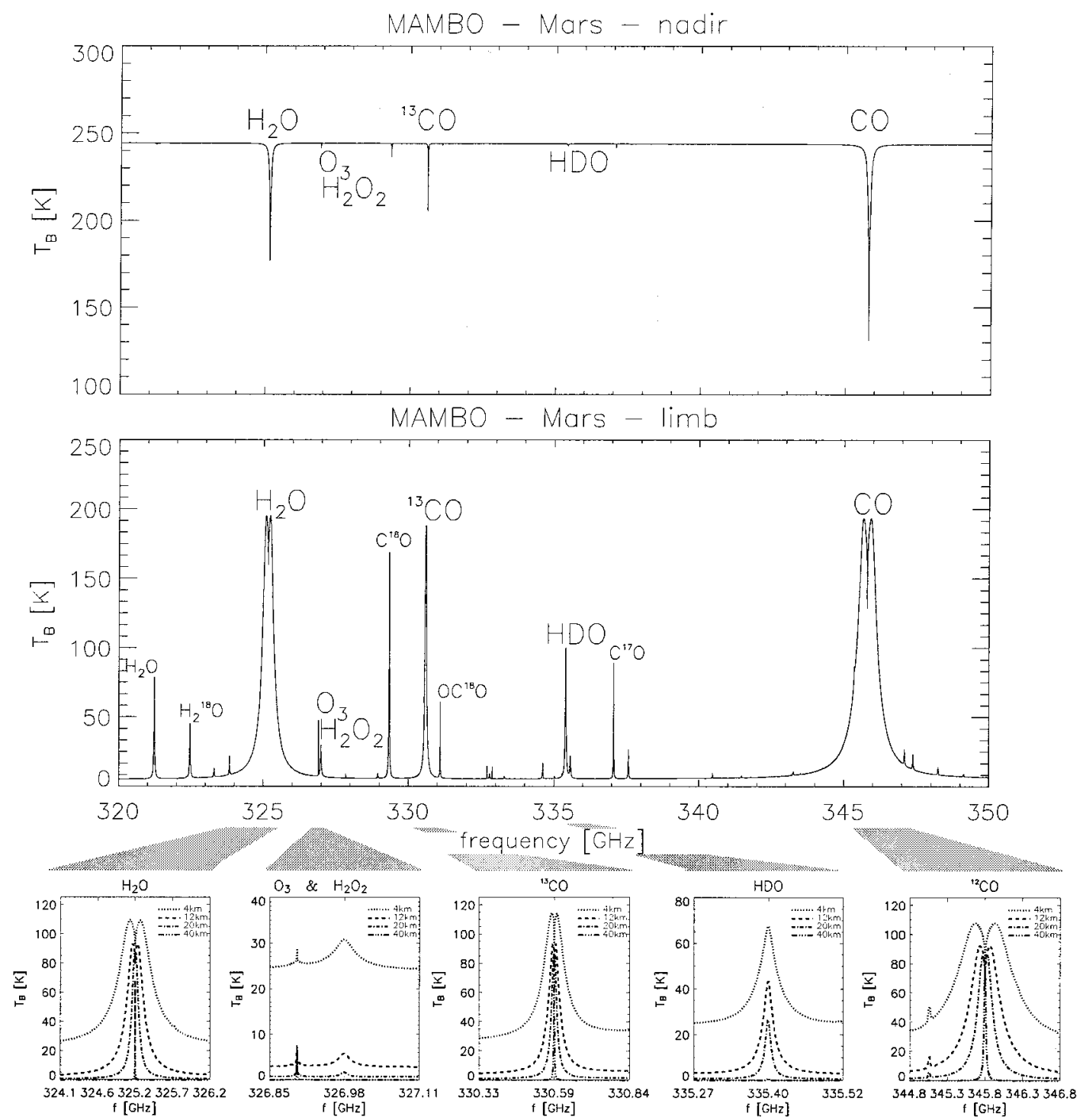

Fig. 1. MOLIERE-5 model calculations in the 320-350-GHz range for standard atmospheric conditions. In the nadir observation geometry the transitions appear as absorption lines viewed against the blackbody radiation of the warmer surface (top). By pointing at the limb, an observation system would measure the atmospheric line emission against the weak cosmic background radiation (middle). The tangent altitude of the limb view shown in this example is $6 \mathrm{~km}$. Bottom: model calculations for the individual double-sideband receiver bands of $\mathrm{H}_{2} \mathrm{O}(325.153 \mathrm{GHz}), \mathrm{O}_{3}$ and $\mathrm{H}_{2} \mathrm{O}_{2}$ (326.901 and $\left.326.982 \mathrm{GHz}\right),{ }^{13} \mathrm{CO}(330.588 \mathrm{GHz}), \mathrm{HDO}(335.396 \mathrm{GHz})$, and ${ }^{12} \mathrm{CO}(345.796$ $\mathrm{GHz})$ at selected tangent altitudes $(4,12,20$, and $40 \mathrm{~km})$.

A priori errors in the target species volume mixing ratios (VMR) of $3 \times 10^{-4}$ for $\mathrm{H}_{2} \mathrm{O}, 5 \times 10^{-7}$ for $\mathrm{HDO}$, and $3 \times 10^{-7}$ for $\mathrm{O}_{3}$ and $\mathrm{H}_{2} \mathrm{O}_{2}$ were chosen, which means that uncertainties were constant over altitude and that parameters were assumed to be uncorrelated. A somewhat smaller uncertainty of $20 \%$ of the maximum of the corresponding a priori profile was used for the less-variable species ${ }^{12} \mathrm{CO}\left(\sim 1.6 \times 10^{-4}\right),{ }^{13} \mathrm{CO}$ $\left(\sim 1.2 \times 10^{-6}\right)$ and for continuum $\mathrm{CO}_{2}(\sim 0.18)$. An $a$ priori error of $20 \mathrm{~K}$ was chosen for temperature, which should largely cover the expected uncertainty and variability about a climatological $a$ priori value. Abrupt global temperature increases of 5-15 K, for example, have been observed during intense dust storm events. ${ }^{11,12}$ The $a$ priori error of the scan bias, representing the remaining uncertainty after satellite atti- tude reconstruction, was assumed to be $0.01^{\circ}$ $(\sim 500 \mathrm{~m})$, whereas the ground temperature was assumed to be uncertain to $5 \mathrm{~K}$ after being retrieved from nadir continuum observations. Note that the values of the a priori errors stated here correspond to the assumed $1-\sigma$ uncertainties of the retrieval parameters.

\section{Results}

\section{A. Retrievals of Constituents}

Results of the nonlinear retrieval simulations for the target species $\mathrm{H}_{2} \mathrm{O}$, $\mathrm{HDO}, \mathrm{H}_{2} \mathrm{O}_{2}$, and $\mathrm{O}_{3}$ are presented in Figs. 2-4. The left-hand sides of the figures show the assumed (true) and the retrieved volume mixing 

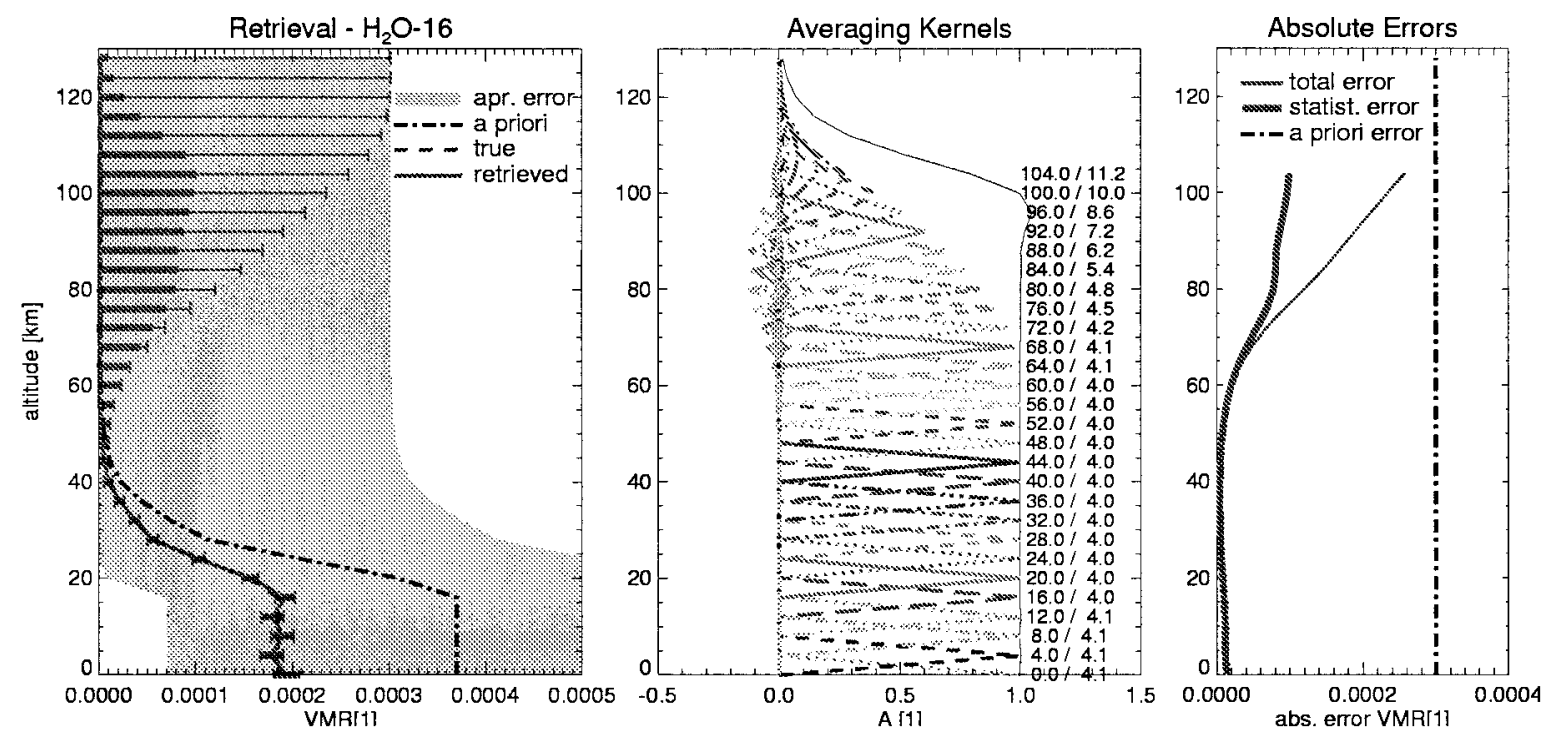

Fig. 2. Results of the nonlinear retrieval simulations for $\mathrm{H}_{2} \mathrm{O}$ at $325.153 \mathrm{GHz}$. Left, retrieved, a priori, and true profiles (see legend). Thick error bars indicate the retrieval error that is due to intrinsic receiver noise. The total retrieval error, also including the smoothing error that is due to the limited altitude resolution, is given by the thin error bars. Shaded area: assumed a priori error. Middle: averaging kernel functions for each retrieval level. The altitude resolution (FWHM) of the measurement is indicated for each retrieval level. The envelope is the measurement response. Values close to 1 indicate the altitude range where the information from the measurement dominates the a priori information. Right: retrieval errors.

ratio profiles. Error bars indicate the statistical errors that are due to intrinsic receiver noise as well as the total error, which also includes contributions from the smoothing error due to the limited altitude resolution of the simulated measurement. Additionally, the a priori (or first-guess) profile is provided, along with its assumed $1-\sigma$ uncertainty. For clarity, the absolute retrieval errors are plotted on the righthand side of each figure. The middle graph provides the averaging kernel functions for each retrieval altitude level. The full width at half-maximum (FWHM) of these functions are reasonable estimates of the altitude resolution of a given observation sys- tem and are also shown. Moreover, the sum over all averaging kernel functions at a given altitude level provides the total measurement response: If the value is close to 1 , the retrieved parameter is determined by the measurement; values close to 0 indicate that the information comes entirely from the $a$ priori parameter.

The standard model assumes a water-vapor profile that corresponds to a total column of 17 precipitable micrometers $(\mathrm{pr}-\mu \mathrm{m})$, as is typical for midlatitude summer conditions. ${ }^{3,14}$ The results of the retrieval simulation for this case are shown in Fig. 2. Information on $\mathrm{H}_{2} \mathrm{O}$ from the measurement is theoretically
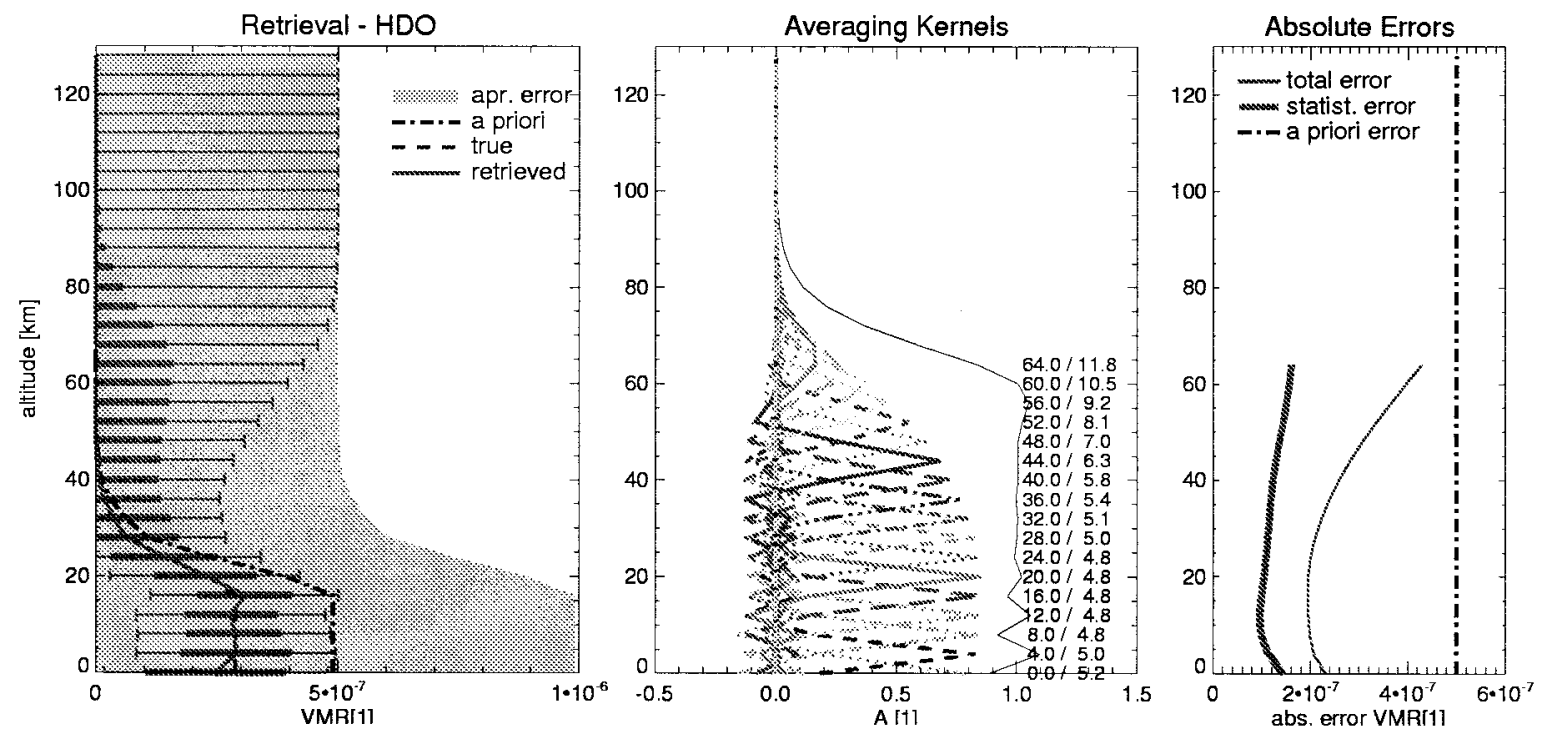

Fig. 3. Results of the nonlinear retrieval simulations for HDO at $335.396 \mathrm{GHz}$. See the caption of Fig. 2 for an explanation. 

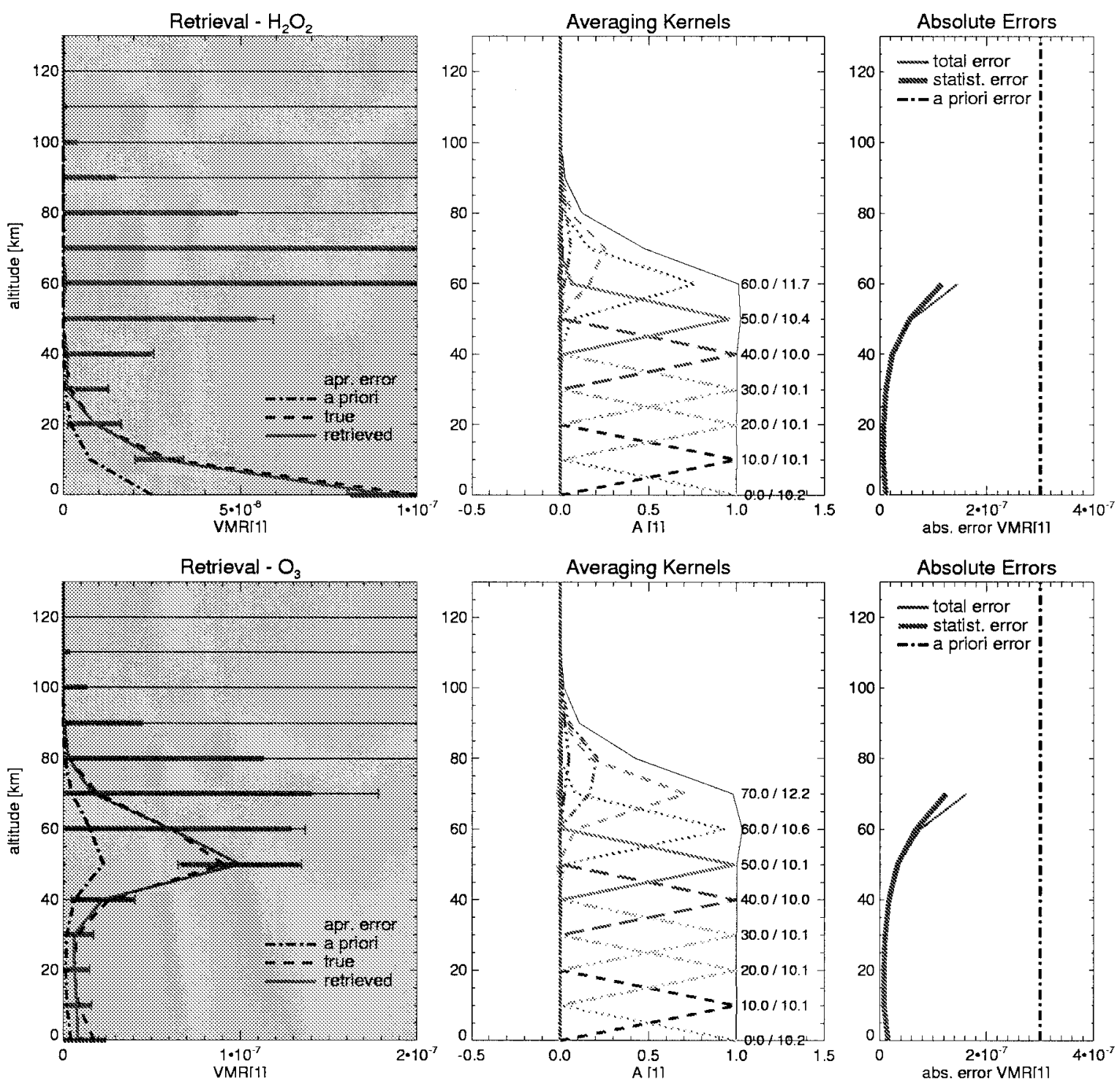

Fig. 4. Results of the nonlinear retrieval simulations for the species $\mathrm{H}_{2} \mathrm{O}_{2}$ at $326.982 \mathrm{GHz}$ (top) and $\mathrm{O}_{3}$ at $326.901 \mathrm{GHz}$ (bottom), retrieved simultaneously on an inversion altitude grid of $10-\mathrm{km}$ resolution. See the caption of Fig. 2 for an explanation. The $a$ priori error for $\mathrm{H}_{2} \mathrm{O}_{2}$ and $\mathrm{O}_{3}$ is $3 \times 10^{-7}$.

available up to $100 \mathrm{~km}$ with a vertical resolution of the order of the scan readout interval of $\sim 4 \mathrm{~km}$ below $\sim 70 \mathrm{~km}$. The corresponding measurement precision in the mixing ratio depends strongly on altitude: Whereas below $50 \mathrm{~km}$ the error that is due to measurement noise is smaller than $\sim 1 \times 10^{-5}$, it increases to values of the order of $5-10 \times 10^{-5}$ above. Best values of the measurement precision of $\sim 5$ $\times 10^{-6}$ are obtained at $40 \mathrm{~km}$. The relative error is of the order of 5-10\% below $30 \mathrm{~km}$ and increases above because of the decreasing $\mathrm{H}_{2} \mathrm{O}$ mixing ratio. Compared to the expected mixing ratios of the standard scenario, useful information can practically be retrieved on a single-scan basis to roughly $40-45 \mathrm{~km}$.

For comparison, in nadir geometry one also may retrieve water vapor from 4 to $60 \mathrm{~km}$ with a precision of the order of $5 \times 10^{-5}$ from a single measurement with an integration time of $5 \mathrm{~s}$ but with a considerably poorer altitude resolution ranging from $10 \mathrm{~km}$ in the lowest layers to $20 \mathrm{~km}$ at the upper limit of the exploitable altitude range. The results of this simulation are shown in Fig. 5. The estimated error that results from statistical receiver noise exceeds the mixing ratios of our theoretical profile above $\sim 30 \mathrm{~km}$.

Because water vapor is known to show a high seasonal variability, ${ }^{14}$ we also investigated extreme cases (Fig. 5). For extremely wet conditions (column $\sim 120$ pr- $\mu \mathrm{m}$ ), corresponding to an upper limit for the water column at high latitudes in the summer Northern Hemisphere, we obtained results similar to those for standard conditions above approximately $15-20 \mathrm{~km}$, whereas at lower altitudes the signal-to-noise ratio is affected by self-absorption of the strong water-vapor line. The relative error below $30 \mathrm{~km}$ is still of the order 

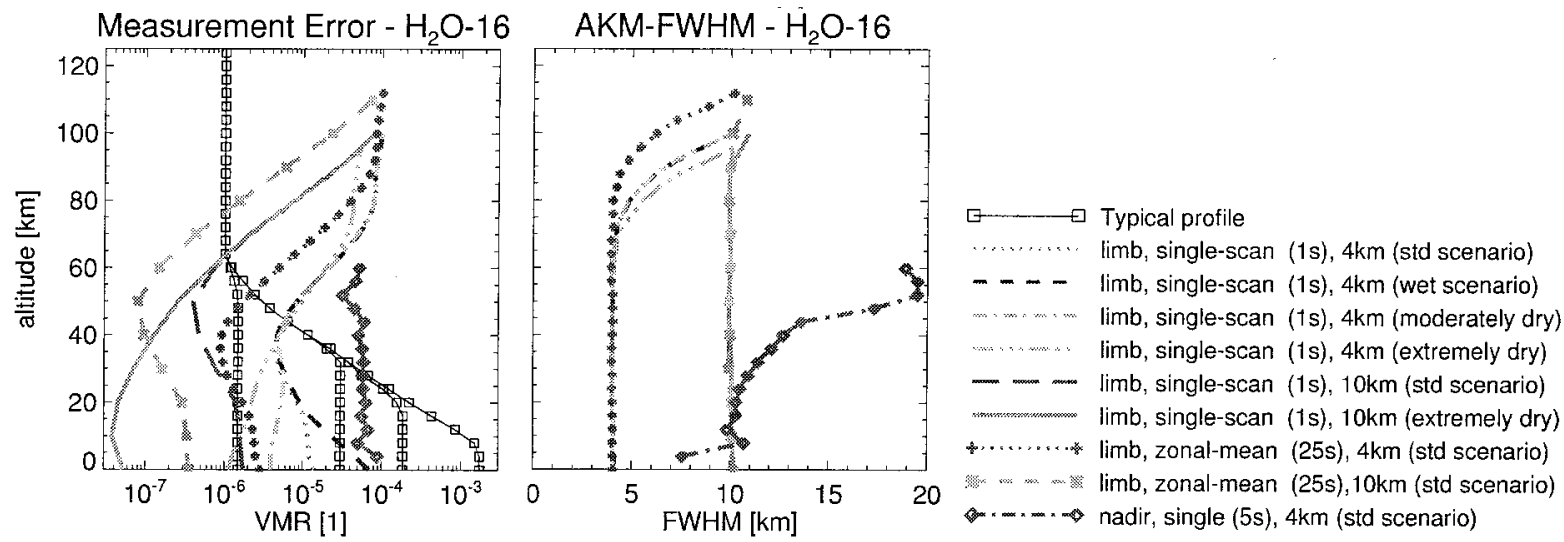

Fig. 5. Comparison of estimated measurement precision (left) and altitude resolution (right) achievable from single-scan (1-s), zonal-mean (25-s), and nadir (5-s) retrievals of $\mathrm{H}_{2} \mathrm{O}$ at $325.153 \mathrm{GHz}$. Also shown are retrieval errors obtained with the assumption of a reduced inversion altitude grid of $10-\mathrm{km}$ resolution. Typical and extreme water vapor profiles (extremely wet, $120 \mathrm{pr}-\mu \mathrm{m}$; standard, $17 \mathrm{pr}-\mu \mathrm{m}$; moderately dry, 3 pr- $\mu \mathrm{m}$; extremely dry, $0.15 \mathrm{pr}-\mu \mathrm{m}$ ), are indicated for comparison.

of $5-10 \%$. Even in a moderately dry atmosphere (column $\sim 3 \mathrm{pr}-\mu \mathrm{m}$ ), to be expected at middle latitudes of the winter Southern Hemisphere, water vapor can still be measured up to approximately $40-45 \mathrm{~km}$ with a vertical resolution of the order of $4 \mathrm{~km}$ and a precision in the range $2-6 \times 10^{-6}$. These values for measurement precision, which are not affected by selfabsorption, represent the noise-equivalent limit for the retrieval of mixing ratios from the spectral measurements of a single limb scan and correspond roughly to a total water column of $0.15-0.2 \mathrm{pr}-\mu \mathrm{m}$. A profile representing extremely dry winter pole conditions with a $\mathrm{H}_{2} \mathrm{O}$ column of $\sim 0.15 \mathrm{pr}-\mu \mathrm{m}$ is shown in Fig. 5 for comparison.

Averaging of spectra at the price of considerably degraded spatial resolution would allow us to reduce further the statistical error caused by intrinsic receiver noise and thus to obtain profile information at higher altitudes or even under extremely dry atmospheric conditions. Assuming, for example, zonal averages with an effective integration time of $25 \mathrm{~s}$, useful information on $\mathrm{H}_{2} \mathrm{O}$ could be obtained with $4-\mathrm{km}$ resolution up to $\sim 50 \mathrm{~km}$ if the corresponding retrieval error were compared with the mixing ratios of wet, standard, or moderately dry conditions (Fig. 5 ). This information would still be useful to constrain chemical-dynamical models of the atmosphere.

It should also be noted that for limb observations there is a trade-off between the resolution of the retrieval altitude grid and the value of the statistical retrieval error. By increasing the retrieval grid step, one obtains a smaller retrieval error and vice versa, according to the information from measurements at given tangent altitudes that contribute to the retrieved mixing ratio at a certain level. The previously derived quantitative estimates of the measurement capabilities for submillimeter-wave limb sounding have therefore to be considered in the context of a retrieval grid with $4-\mathrm{km}$ resolution. For comparison, retrieval simulations were also performed with a retrieval grid with $10-\mathrm{km}$ resolution. The single-profile retrieval on the 10-km grid for standard conditions indicates error measurement that is due to measurement noise smaller than $2 \times 10^{-6}$ below $60 \mathrm{~km}$ with a best value of $\sim 5 \times 10^{-7}$ at $50 \mathrm{~km}$. Compared with the retrieval on the 4-km grid for the same standard atmospheric conditions, we thus obtain an improvement of roughly 1 order of magnitude and an extension of the useful measurement range to $\sim 60 \mathrm{~km}$. Zonal mean (25-s) retrievals on the $10-\mathrm{km}$ grid would provide information even up to $70-75 \mathrm{~km}$ if we compared them with the expected mixing ratios in this altitude range. Moreover, single-scan retrievals under extremely dry atmospheric conditions do not suffer from self-absorption of the signal at low altitudes and would provide useful results up to $\sim 60 \mathrm{~km}$ on the 10-km retrieval grid (see also Fig. 5).

The HDO retrieval simulation for standard atmospheric conditions shown in Fig. 3, resulted in a measurement response close to 1 up to $\sim 60 \mathrm{~km}$. The altitude resolution is of the order of $\sim 5 \mathrm{~km}$ below $35 \mathrm{~km}$ and degrading above, with increasing altitude. The retrieval precision is approximately 1-1.5 $\times 10^{-7}(\sim 20-30 \%$ up to $20-25 \mathrm{~km})$ for mixing ratios retrieved on the $4-\mathrm{km}$ grid. For extremely wet conditions, similar results were obtained (see Fig. 6).

As for $\mathrm{H}_{2} \mathrm{O}$, the precision of retrieval and thus the useful altitude range can be improved by averaging of measurements, which is useful in particular for the study of isotope fractionation above the condensation level, as discussed, for example, by Fouchet and Lellouch. ${ }^{31}$ Our standard HDO profile was derived from the standard $\mathrm{H}_{2} \mathrm{O}$ profile and corresponds below $20 \mathrm{~km}$ to a $\mathrm{D} / \mathrm{H}$ ratio of five times the isotopic ration in standard mean ocean water (SMOW) of 1.5576 $\times 10^{-4}$, a depletion of $80 \%$ above $\sim 45 \mathrm{~km}$, and a linear transition from 20 to $45 \mathrm{~km}$. A profile for extremely wet conditions was derived in a similar way from the wet $\mathrm{H}_{2} \mathrm{O}$ profile, but the assumed depletion above $45 \mathrm{~km}$ was only $20 \%$. The error in the $\mathrm{D} / \mathrm{H}$ ratio derived from the single-scan precision of $\mathrm{H}_{2} \mathrm{O}$ 


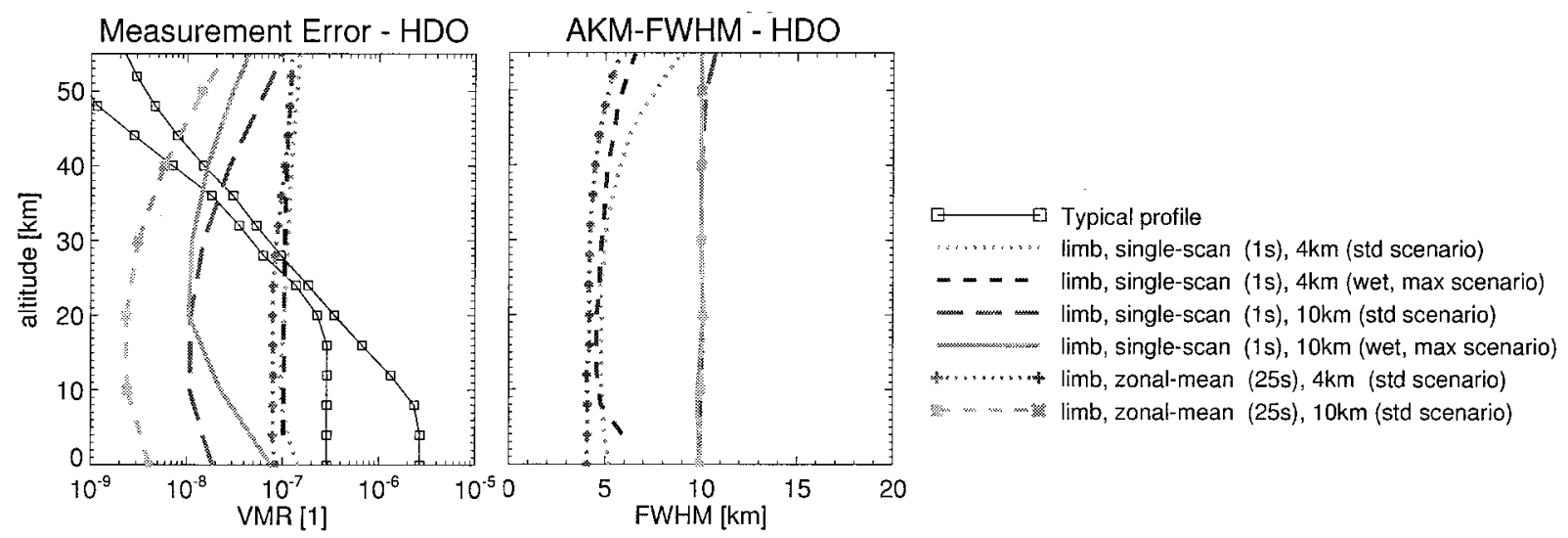

Fig. 6. Comparison of estimated measurement precision (left) and altitude resolution (right) achievable from single-scan (1-s) and zonal-mean (25-s) retrievals of HDO at $335.396 \mathrm{GHz}$. Also shown are retrieval errors obtained with the assumption of a reduced inversion altitude grid of 10-km resolution. Profiles for standard and wet (upper limit) atmospheric conditions are also shown.

and HDO when it is retrieved on the 4-km retrieval grid increases rapidly above $\sim 20 \mathrm{~km}$, which is insufficient if the isotopic fractionation above the condensation level is to be studied (see Fig. 7). However, retrieval simulations on a grid with reduced resolution of $10 \mathrm{~km}$ yield meaningful information on the $\mathrm{D} / \mathrm{H}$ ratio up to an altitude of $\sim 30 \mathrm{~km}$ for single-scan retrievals and up to $\sim 35 \mathrm{~km}$ for zonal mean (25-s) retrievals. Obtaining information with better altitude resolution will require more extensive averaging.

The results of the retrieval simulations for $\mathrm{H}_{2} \mathrm{O}_{2}$ and $\mathrm{O}_{3}$ are presented in Figs. 4 and 8. The estimated measurement precision for $\mathrm{H}_{2} \mathrm{O}_{2}$, if it was retrieved on the standard $4-\mathrm{km}$ retrieval grid given by the tangent altitudes of the measurement, was found to be approximately $5-10 \times 10^{-8}$ in the $0-60-\mathrm{km}$ altitude range with a corresponding vertical resolution better than $5 \mathrm{~km}$ below $30 \mathrm{~km}$. In the same band, an ozone profile can be simultaneously retrieved up to $70 \mathrm{~km}$ with retrieval precision and altitude resolution of the same order of magnitude as for $\mathrm{H}_{2} \mathrm{O}_{2}$.
Given the expected mixing ratios of these species, useful information can thus be obtained only if data are averaged. Figure 4 shows therefore the results of single-scan retrievals on a grid with a reduced altitude resolution of $10 \mathrm{~km}$. For $\mathrm{H}_{2} \mathrm{O}_{2}$ the resultant measurement error is smaller than $1 \times 10^{-8}$ below $25 \mathrm{~km}$, allowing useful information to be obtained up to an altitude of 20-30 km. Ozone may be retrieved up to $\sim 50 \mathrm{~km}$ with a precision better than $3 \times 10^{-8}$. Figure 8 summarizes the theoretical measurement capabilities for single-profile and zonally averaged data products of $\mathrm{H}_{2} \mathrm{O}_{2}$ and $\mathrm{O}_{3}$. Note that for $\mathrm{HDO}, \mathrm{H}_{2} \mathrm{O}_{2}$, and $\mathrm{O}_{3}$ the sensitivity of nadir sounding with an integration time of $5 \mathrm{~s}$ does not allow profiles to be retrieved.

\section{B. Temperature Retrieval}

Temperature information is contained in the limb measurements of optically thick lines such as ${ }^{12} \mathrm{CO}$ at $345.796 \mathrm{GHz}$ and ${ }^{13} \mathrm{CO}$ at $330.588 \mathrm{GHz}$ because the measured temperature is close to the atmospheric

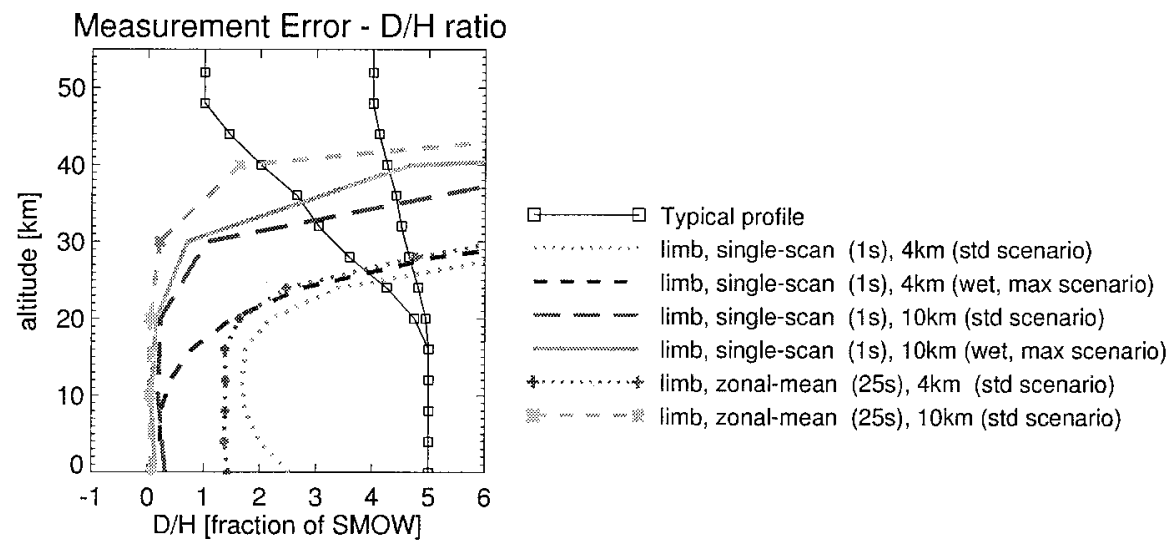

Fig. 7. Comparison of measurement precision for the D/H ratio derived from single-scan (1-s) and zonal-mean (25-s) retrievals of HDO at $335.1 \mathrm{GHz}$ and $\mathrm{H}_{2} \mathrm{O}$ at $325.1 \mathrm{GHz}$. Also shown are retrieval errors obtained with the assumption of a reduced inversion altitude grid of $10-\mathrm{km}$ resolution. Profiles with depletion of $80 \%$ and $20 \%$, derived from the standard and wet scenario for $\mathrm{H}_{2} \mathrm{O}$ and $\mathrm{HDO}$, are indicated for comparison. 

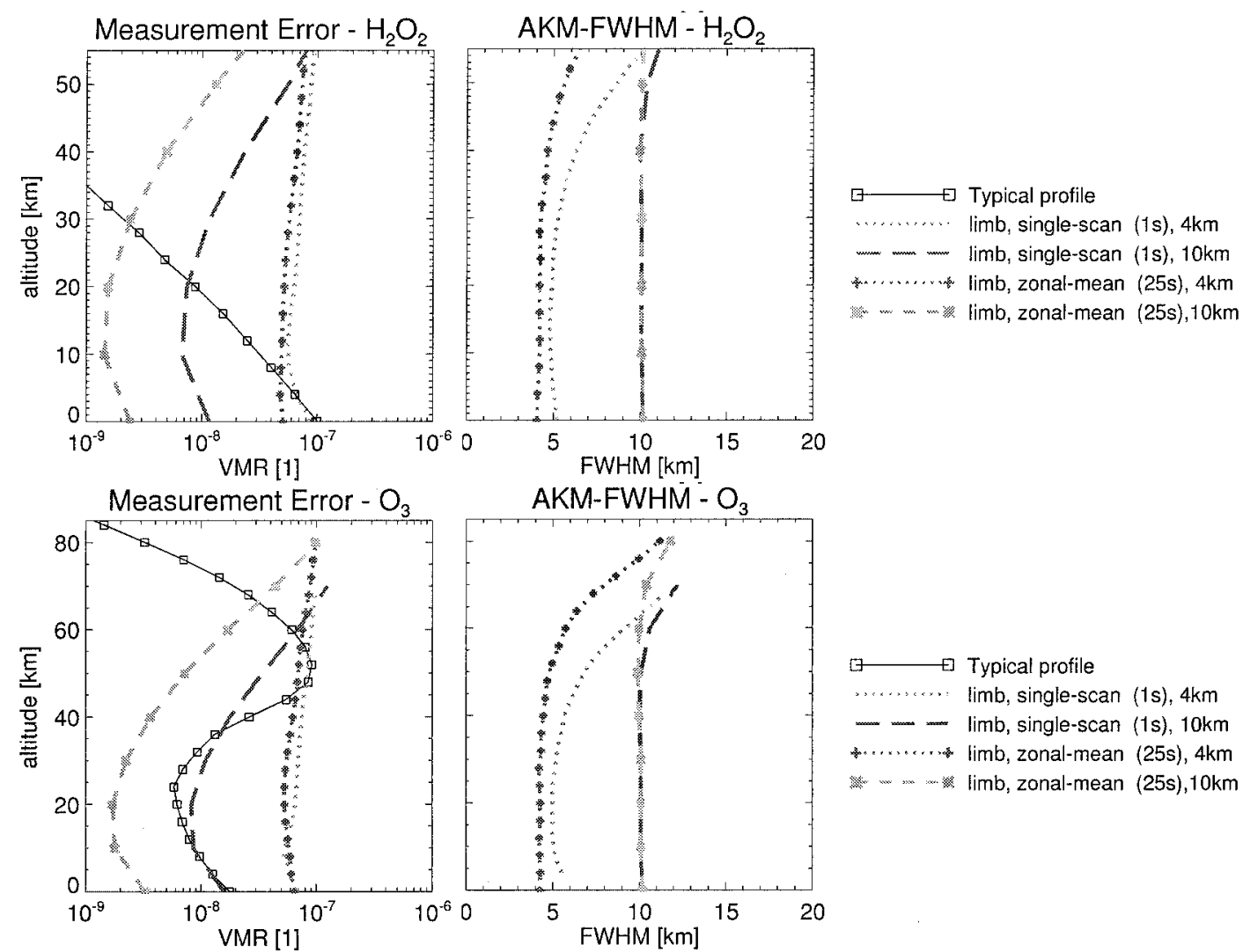

Fig. 8. Comparison of estimated measurement precision (left) and altitude resolution (right) achievable from single-scan (1-s), zonal-mean (25-s), and nadir (5-s) retrievals of $\mathrm{H}_{2} \mathrm{O}_{2}$ at $326.982 \mathrm{GHz}$ (top) and $\mathrm{O}_{3}$ at $326.901 \mathrm{GHz}$ (bottom). Retrieval errors obtained from inversion simulations with the assumption of a reduced inversion altitude grid of $10-\mathrm{km}$ resolution are also presented. Typical profiles are indicated for comparison.

temperature at the altitude where saturation occurs. This characteristic behavior is shown in Fig. 9, where brightness temperatures are plotted for both lines under consideration as a function of tangent altitudes. The temperature profile, converted to brightness temperatures, is also shown. It is evident that the maximum values of the spectra follow the atmospheric temperature profile up to altitudes of $\sim 60 \mathrm{~km}$ for ${ }^{13} \mathrm{CO}$ and $\sim 90 \mathrm{~km}$ for ${ }^{12} \mathrm{CO}$. The combination of the information from both lines should consequently permit temperature to be retrieved up to $\sim 90 \mathrm{~km}$, as shown in the combined double-sideband spectrum of ${ }^{12} \mathrm{CO}$ and ${ }^{13} \mathrm{CO}$ at the right in Fig. 9.

Retrieval of temperature from these two long-lived molecules has the further advantage that the mixing ratio is relatively well known and much less variable compared with other species with strong lines such as water vapor. For the simulations we assume an $a$ priori error of $20 \%$ (of the profile maximum) as a conservative worst-case estimate for the expected uncertainty in the ${ }^{12} \mathrm{CO}$ and ${ }^{13} \mathrm{CO}$ mixing ratios.

Nonlinear retrieval simulations with these assumptions resulted indeed in a significant measurement response range for temperature up to $\sim 85 \mathrm{~km}$, as shown in Fig. 10. For this example the altitude resolution is of the order of $4-5 \mathrm{~km}$ up to $55 \mathrm{~km}$ and in the range $5-10 \mathrm{~km}$ above. The precision is in the range 3-6 $\mathrm{K}$ for temperature retrievals on the $4-\mathrm{km}$ retrieval grid. Simulations that employed various different temperature profiles yielded similar results, and the upper altitude limit of the temperature retrieval was typically in the range $85-95 \mathrm{~km}$.

Simultaneously, mixing ratio profiles for ${ }^{12} \mathrm{CO}$ and ${ }^{13} \mathrm{CO}$ were estimated. ${ }^{12} \mathrm{CO}$ can be retrieved up to $100 \mathrm{~km}$ with an error smaller than $1 \times 10^{-4}$ (or $5-10 \%)$. The altitude resolution was better than $5 \mathrm{~km}$ below $40 \mathrm{~km}$. Note that a minimum in the measurement response was observed near $80 \mathrm{~km}$, which is obviously correlated with the temperature minimum. For this extreme example, the signal-to-noise ratio of the measurement in this altitude range is thus not sufficient to retrieve ${ }^{12} \mathrm{CO}$ along with temperature. For ${ }^{13} \mathrm{CO}$, the approximate range with significant information from the measurement is $0-75 \mathrm{~km}$, and the measurement precision is estimated to be better than $1 \times 10^{-6}(5-10 \%)$. The FWHM value of the averaging kernel functions is smaller than $7 \mathrm{~km}$ for retrieval levels below $40 \mathrm{~km}$.

Figure 11 compares the results obtained for temperature to nadir and zonal-mean retrievals. Zonalmean temperature profiles (integration time $25 \mathrm{~s}$ ) typically extend to approximately $90-100 \mathrm{~km}$ with an altitude resolution of $4-5 \mathrm{~km}$ below $55 \mathrm{~km}$ (increas- 

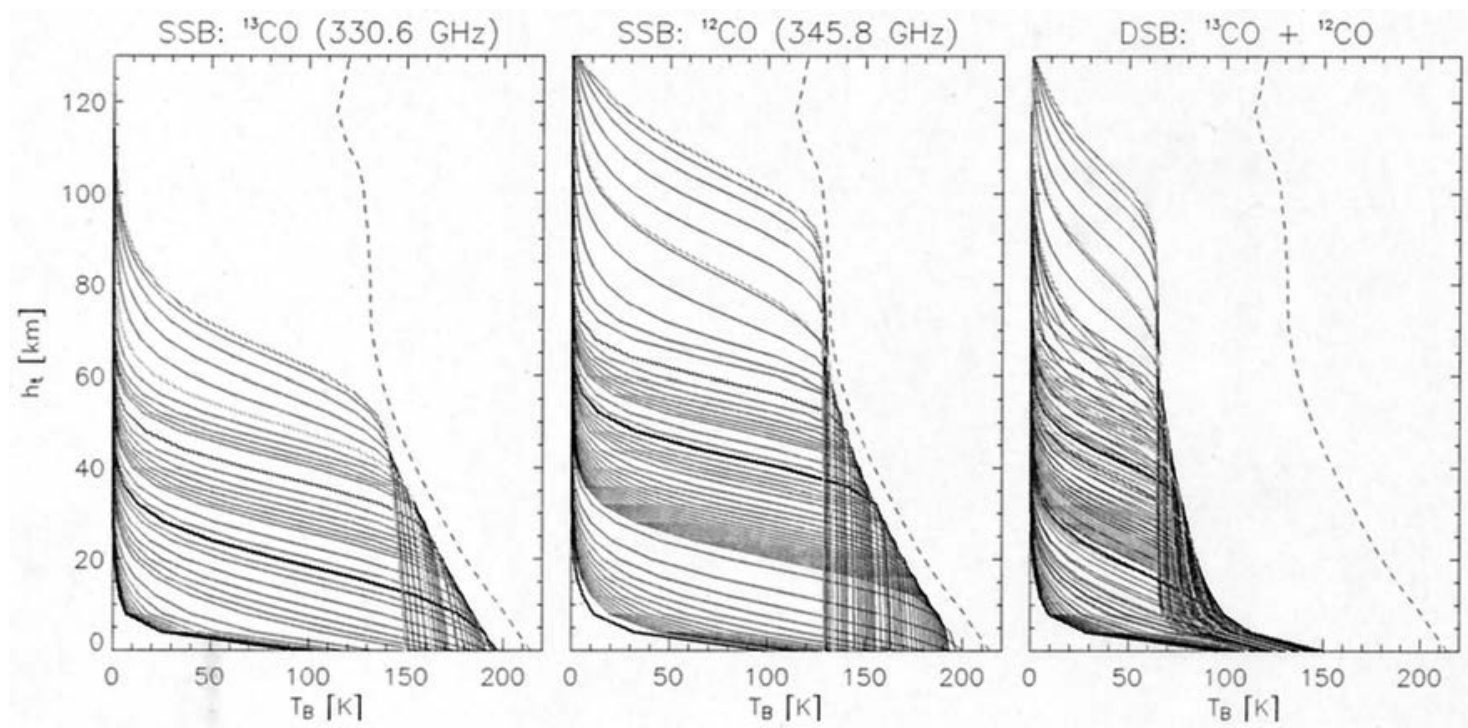

Fig. 9. MOLIERE-5 model calculations for selected channels of the ${ }^{13} \mathrm{CO}$ (left) and ${ }^{12} \mathrm{CO}$ (middle) bands, assuming standard atmospheric conditions. The curves represent brightness temperatures for individual channels as a function of tangent altitude (SSB: single-sideband spectrum). The resultant double-sideband spectrum (DSB) is shown at the right. The temperature profile, converted to brightness temperatures, is indicated as well (dashed curves).

ing to $10-15 \mathrm{~km}$ above) and a precision of the order of $1-2 \mathrm{~K}$. Zonal-mean (25-s) retrievals on the $10-\mathrm{km}$ grid would even allow information to be obtained up to $\sim 120 \mathrm{~km}$. Nadir observations (integration time, 5 s) would provide temperature information up to an altitude of $\sim 70 \mathrm{~km}$ with a precision of $5 \mathrm{~K}$ but with considerably poorer vertical resolution that increases with altitude from $\sim 6$ to $16 \mathrm{~km}$, which may cause considerable difficulties in reproducing the true profile above $\sim 40 \mathrm{~km}$. Information on the mixing ratios of the $\mathrm{CO}$ isotopes are not contained in a 5-s nadir measurement, which means in turn that the nadir temperature retrieval is relatively insensitive to variations in the $\mathrm{CO}$ mixing ratio.

An overview of the measurement capabilities of a state-of-the-art submillimeter-wave limb sounder operating in the $320-350-\mathrm{GHz}$ range is provided in Table 2 .

\section{Alternatives for Line Selection}

The search for a combination of target bands that contain suitable spectral lines of the most important target species $\mathrm{H}_{2} \mathrm{O}$ and $\mathrm{HDO}$ as well as ${ }^{12} \mathrm{CO}$ and ${ }^{13} \mathrm{CO}$ for temperature and wind retrieval in one simple, compact, lightweight, and low-power-consuming instrument is the main driver for the selection of the frequency range of a potential submillimeter-wave limb sounder of the Martian atmosphere. The choice of the $320-350-\mathrm{GHz}$ range is, as demonstrated above, one possible solution for the design of such an instrument. Alternatives for the selection of the frequency bands are now discussed.

${ }^{12} \mathrm{CO}$ as a linear molecule has a simple rotational spectrum with transitions at 115.3, 230.5, 345.8, $461.0,576.3$, and $691.5 \mathrm{GHz}$ for the main isotope. Lines of the isotope ${ }^{13} \mathrm{CO}$ are always found in the vicinity of those of the main isotope at 110.2, 220.4,
330.6, 440.8, 550.9, and $661.1 \mathrm{GHz}$. We showed in Subsection 5.B that the combination of neighboring $\mathrm{CO}$ isotope lines with very different line strengths is highly beneficial to the retrieval of temperature. Strong water-vapor lines close to the CO isotope line pairs are available only at $183.3,325.1,439.2,448.0$, $474.7,489.5$, and $556.9 \mathrm{GHz}$, further restricting the choice. HDO transitions can be found in all the remaining windows: at 225.8, 335.4, 464.9, 479.9, and $481.7 \mathrm{GHz}$. Even stronger HDO lines could be measured at 490.6 or $599.9 \mathrm{GHz}$. Secondary-target species such as $\mathrm{O}_{3}$ and $\mathrm{H}_{2} \mathrm{O}_{2}$ have more-complex spectra with many potential target lines in the submillimeter-wave range and are therefore not critical for the band selection. The millimeter- and submillimeter-wave spectra of $\mathrm{O}_{2}$, with only a few strong transitions at 118.8, 368.5, 424.8, and 487.3 $\mathrm{GHz}$, would, however, influence the choice of an instrument's spectral range if scientific priority were given to measurements of this minor species.

Robust subharmonically pumped mixers, required for a simple design of the instrument optics, are nowadays available for all these spectral ranges. However, the receiver's sensitivity decreases considerably by roughly a factor of 2 from 300 to $600 \mathrm{GHz}$. The antenna's field of view, on the other hand, improves linearly with frequency, and a higher frequency range could therefore be beneficial for the altitude resolution.

In Figs. 12-14 we compare the theoretically achievable measurement precision and altitude resolution for the key parameters temperature, $\mathrm{H}_{2} \mathrm{O}$, and $\mathrm{HDO}$ when they are retrieved from single-scan limb observations of target lines in the $150-650-\mathrm{GHz}$ range. To ensure the comparability of the spectral bands we based the retrieval simulations on the same assumptions about the instrumental characteristics that were previously adopted for the retrievals from the corre- 

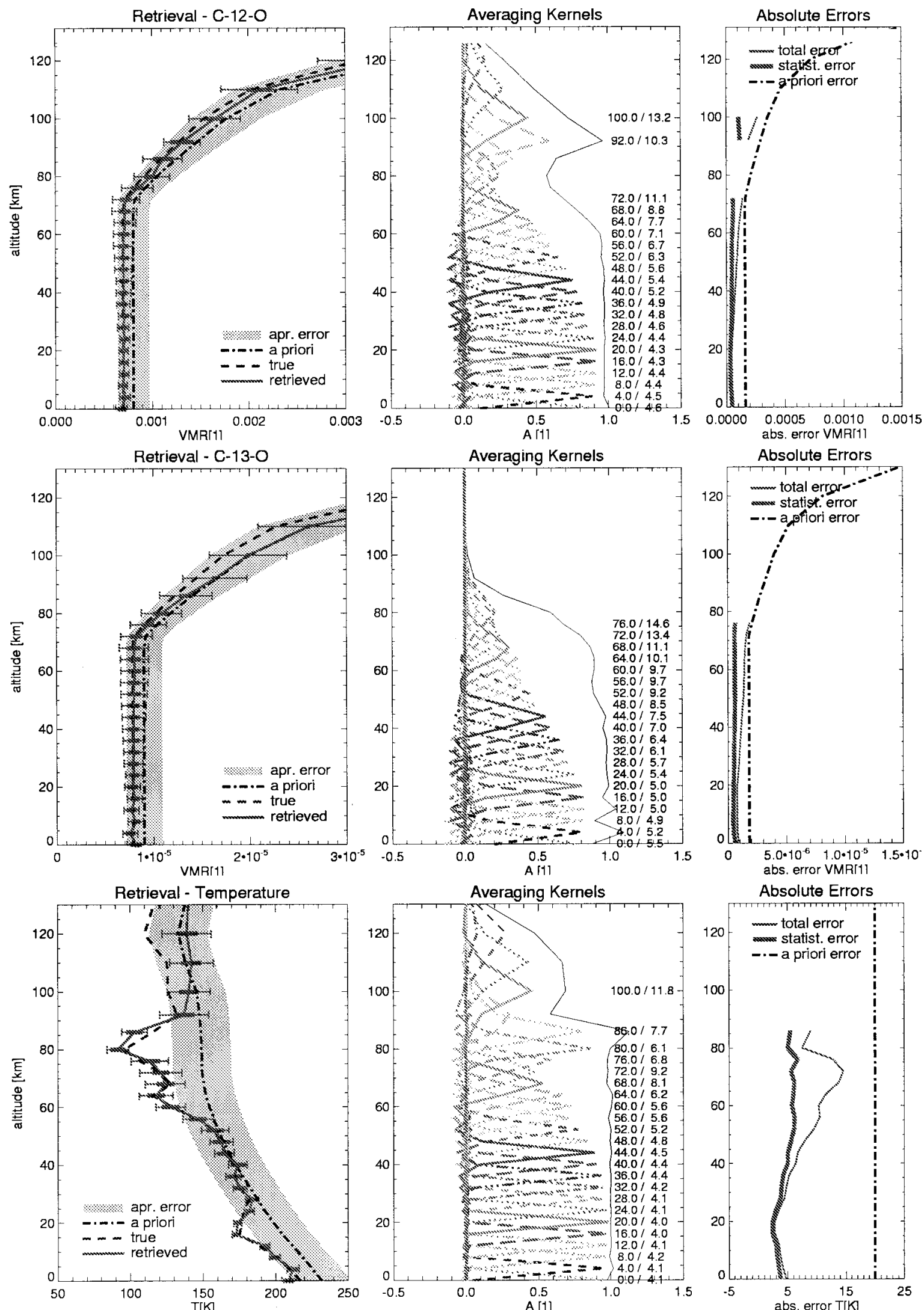

Fig. 10. Results of the nonlinear retrieval simulations for ${ }^{12} \mathrm{CO}$ at $345.796 \mathrm{GHz}$ (top), ${ }^{13} \mathrm{CO}$ at $330.588 \mathrm{GHz}$ (middle), and the simultaneously retrieved temperature. See the caption of Fig. 2 for an explanation. 

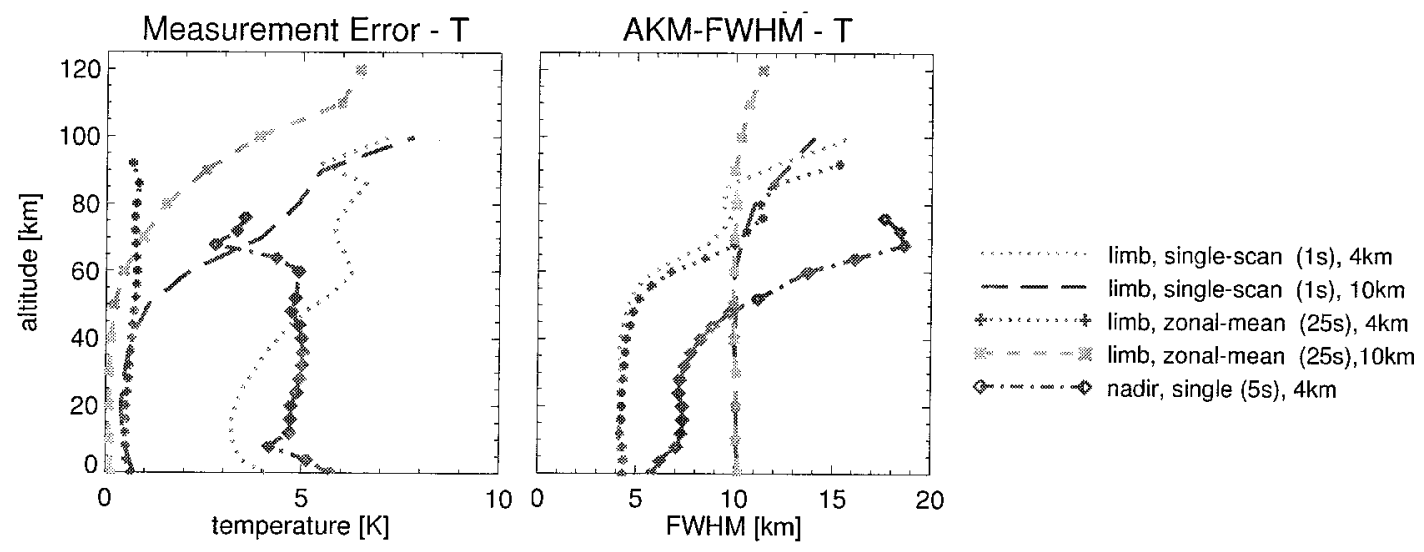

Fig. 11. Comparison of estimated measurement precision (left) and altitude resolution (right) achievable from single-scan (1-s), zonalmean (25-s), and nadir (5-s) temperature retrievals from spectral lines of ${ }^{12} \mathrm{CO}$ at $345.796 \mathrm{GHz}$ and ${ }^{13} \mathrm{CO}$ at $330.588 \mathrm{GHz}$. Also shown are retrieval errors obtained with the assumption of a reduced inversion altitude grid of 10-km resolution.

sponding target lines in the $320-350-\mathrm{GHz}$ range. In particular, calculations were always performed for a double-sideband receiver and for the back-end spectrometer bandwidths and spectral resolutions listed in Table 1. For temperature retrieval from the CO line pairs the intermediate frequency was adjusted to allow for measurements of the ${ }^{12} \mathrm{CO}$ and ${ }^{13} \mathrm{CO}$ lines in the upper and lower sidebands in the same parts of the spectrometer as for the $330-345-\mathrm{GHz}$ case. A linear dependence on frequency was assumed for the deterioration of the receiver noise as well as for the narrowing of the antenna's field of view.
Figure 12 shows the results for the single-scan temperature retrieval from the four $\mathrm{CO}$ isotope line pairs that reside in the $150-650-\mathrm{GHz}$ range. The measurement precision below $\sim 50 \mathrm{~km}$ and the altitude resolution above $\sim 60 \mathrm{~km}$ improve considerably for the higher-frequency bands; this improvement mainly reflects the strongly increasing spectroscopic line strengths with frequency. The narrowing of the antenna's main lobe with increasing frequency might additionally play a role in the improvement of the altitude resolution above $60 \mathrm{~km}$.

A comparison of retrieval results derived from

Table 2. Theoretical Capabilities of a Submillimeter-Wave Limb Sounder in the $320-350-$ GHz Range for Observation of Key Parameters in the Martian Atmosphere ${ }^{a}$

\begin{tabular}{|c|c|c|c|c|c|}
\hline Band & $\begin{array}{c}\text { Species (Integration Time, } \\
\text { Retrieval Grid Step) }\end{array}$ & $\begin{array}{c}v_{0} \\
(\mathrm{GHz})\end{array}$ & $\begin{array}{c}\text { Altitude Resolution } \\
\qquad(\mathrm{km})\end{array}$ & $\begin{array}{l}\text { Altitude Range } \\
(\mathrm{km})\end{array}$ & $\begin{array}{l}\text { 1- } \sigma \text { Precision } \\
\text { (ppv or K) }\end{array}$ \\
\hline \multirow[t]{7}{*}{$\mathrm{A}$} & ${ }^{12} \mathrm{CO}(1 \mathrm{~s})$ & 345.796 & $\leq 5(<40 \mathrm{~km})$ & $0-100$ & $4-10 \times 10^{-5}[5-10 \%]$ \\
\hline & ${ }^{13} \mathrm{CO}(1 \mathrm{~s})$ & 330.588 & $\leq 7(<40 \mathrm{~km})$ & $0-75$ & $5-7 \times 10^{-7}[5-10 \%]$ \\
\hline & $\mathrm{T}(1 \mathrm{~s})$ & & $4-5(<55 \mathrm{~km})$ & $0-85$ & $3-6 \mathrm{~K}$ \\
\hline & $\mathrm{T}(25 \mathrm{~s})$ & & $4-5(<55 \mathrm{~km})$ & $0-110$ & $1-2 \mathrm{~K}$ \\
\hline & $\mathrm{T}(1 s, 10 \mathrm{~km})$ & & $10(<80 \mathrm{~km})$ & $0-100$ & $\leq 1 \mathrm{~K}(<50 \mathrm{~km})$ \\
\hline & $\mathrm{T}(25 \mathrm{~s}, 10 \mathrm{~km})$ & & $10(<100 \mathrm{~km})$ & $0-120$ & $\leq 1 \mathrm{~K}(<70 \mathrm{~km})$ \\
\hline & $\mathrm{T}(5 \mathrm{~s}$, nadir $)$ & & $6-16$ & $0-70$ & $\sim 5 \mathrm{~K}$ \\
\hline \multirow[t]{5}{*}{ B } & $\mathrm{H}_{2} \mathrm{O}$ & 325.153 & $\sim 4(<70 \mathrm{~km})$ & $0-100$ & $\leq 1 \times 10^{-5}(<50 \mathrm{~km})$ \\
\hline & $\mathrm{H}_{2} \mathrm{O}(25 \mathrm{~s})$ & & $\sim 4(<85 \mathrm{~km})$ & $0-110$ & $\leq 3 \times 10^{-6}(<50 \mathrm{~km})$ \\
\hline & $\mathrm{H}_{2} \mathrm{O}(1 \mathrm{~s}, 10 \mathrm{~km})$ & & 10 & $0-100$ & $\leq 2 \times 10^{-6}(<60 \mathrm{~km})$ \\
\hline & $\mathrm{H}_{2} \mathrm{O}(25 \mathrm{~s}, 10 \mathrm{~km})$ & & 10 & $0-110$ & $\leq 1 \times 10^{-6}(<75 \mathrm{~km})$ \\
\hline & $\mathrm{H}_{2} \mathrm{O}$ (5 s, nadir $)$ & & $10-20$ & $4-60$ & $4-6 \times 10^{-5}$ \\
\hline \multirow[t]{4}{*}{$\mathrm{C}$} & $\operatorname{HDO}(1 \mathrm{~s})$ & 335.396 & $\sim 5(<35 \mathrm{~km})$ & $0-60$ & $10-15 \times 10^{-8}(<40 \mathrm{~km})$ \\
\hline & $\operatorname{HDO}(25 \mathrm{~s})$ & & $\sim 4(<35 \mathrm{~km})$ & $0-75$ & $8-15 \times 10^{-8}(<40 \mathrm{~km})$ \\
\hline & $\mathrm{HDO}(1 \mathrm{~s}, 10 \mathrm{~km})$ & & 10 & $0-60$ & $2-3 \times 10^{-8}(<40 \mathrm{~km})$ \\
\hline & $\mathrm{HDO}(25 \mathrm{~s}, 10 \mathrm{~km})$ & & 10 & $0-70$ & $3-6 \times 10^{-9}(<40 \mathrm{~km})$ \\
\hline \multirow[t]{4}{*}{$\mathrm{D}$} & $\mathrm{O}_{3}(1 \mathrm{~s}, 10 \mathrm{~km})$ & 326.901 & 10 & $0-70$ & $1-3 \times 10^{-8}(<50 \mathrm{~km})$ \\
\hline & $\mathrm{O}_{3}(25 \mathrm{~s}, 10 \mathrm{~km})$ & & 10 & $0-80$ & $2-6 \times 10^{-9}(<50 \mathrm{~km})$ \\
\hline & $\mathrm{H}_{2} \mathrm{O}_{2}(1 \mathrm{~s}, 10 \mathrm{~km})$ & 326.982 & 10 & $0-60$ & $\leq 1 \times 10^{-8}(<25 \mathrm{~km})$ \\
\hline & $\mathrm{H}_{2} \mathrm{O}_{2}(25 \mathrm{~s}, 10 \mathrm{~km})$ & & 10 & $0-70$ & $\leq 2 \times 10^{-9}(<25 \mathrm{~km})$ \\
\hline
\end{tabular}

${ }^{a}$ Shown are target line frequencies, altitude resolutions derived from the averaging kernel functions (FWHM), altitude ranges where the a priori contribution is negligible, and single-scan precision for 4- and 10-km step retrieval grids. Results obtained for 5-s nadir observations as well as for 25-s limb (zonal mean) retrievals are also provided for comparison. 

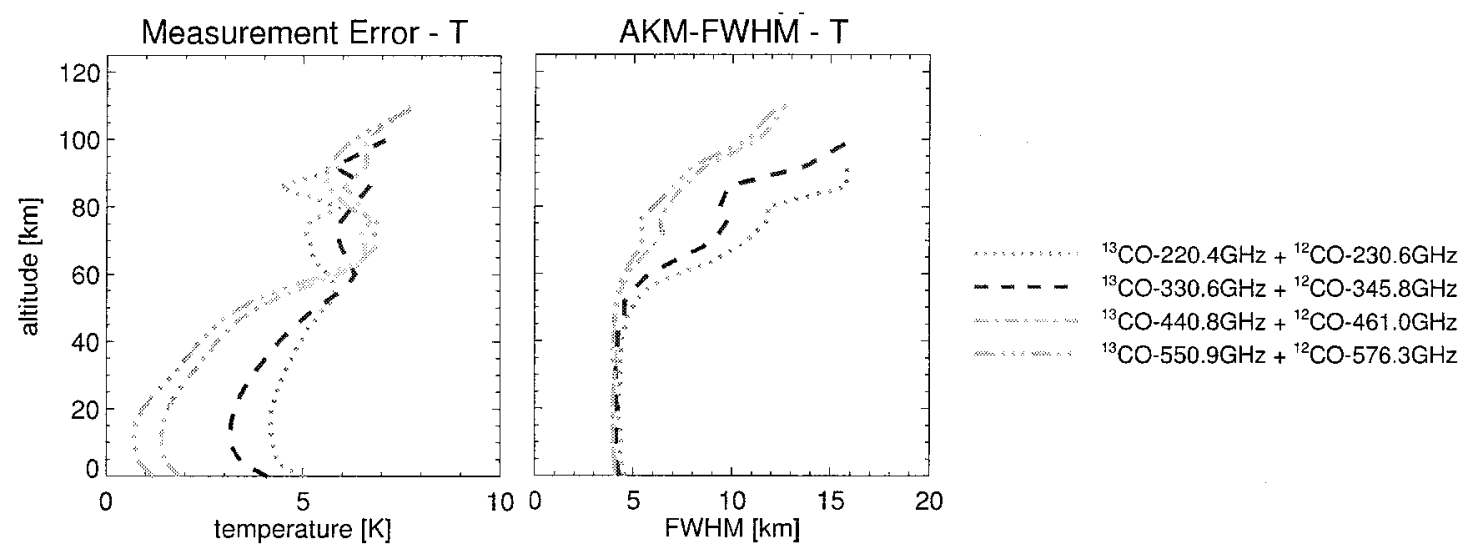

Fig. 12. Comparison of measurement precision (left) and altitude resolution (right) for single-scan profile retrievals of temperature from different $\mathrm{CO}$ isotope line pairs in the $150-650 \mathrm{GHz}$ range.

$\mathrm{H}_{2} \mathrm{O}$ target lines is shown in Fig. 13. Since $\mathrm{H}_{2} \mathrm{O}$ in the Martian atmosphere is characterized by a significant seasonal variability, retrieval simulations were also calculated for extreme dry and wet conditions. The results show that, for the standard and wet conditions, all $\mathrm{H}_{2} \mathrm{O}$ lines considered in the $150-650-\mathrm{GHz}$ range are affected by self-absorption, leading to a considerable degradation of the retrieval precision at low tangent altitudes. In practice, self-absorption should limit the exploitable altitude range, in particular for the strongest lines, because of the strong nonlinearity of the retrieval problem. Consequently, satisfactory results for the strongest water-vapor line at $556.9 \mathrm{GHz}$ are obtained only at altitudes above $20 \mathrm{~km}$ or under extreme dry atmospheric conditions. Good sensitivity can be obtained by observation of the slightly weaker $\mathrm{H}_{2} \mathrm{O}$ lines at $380.2,448.0$, or $620.7 \mathrm{GHz}$, still sufficient for the detection of the low mixing ratios of the dry profile below $20 \mathrm{~km}$ but, in the case of an
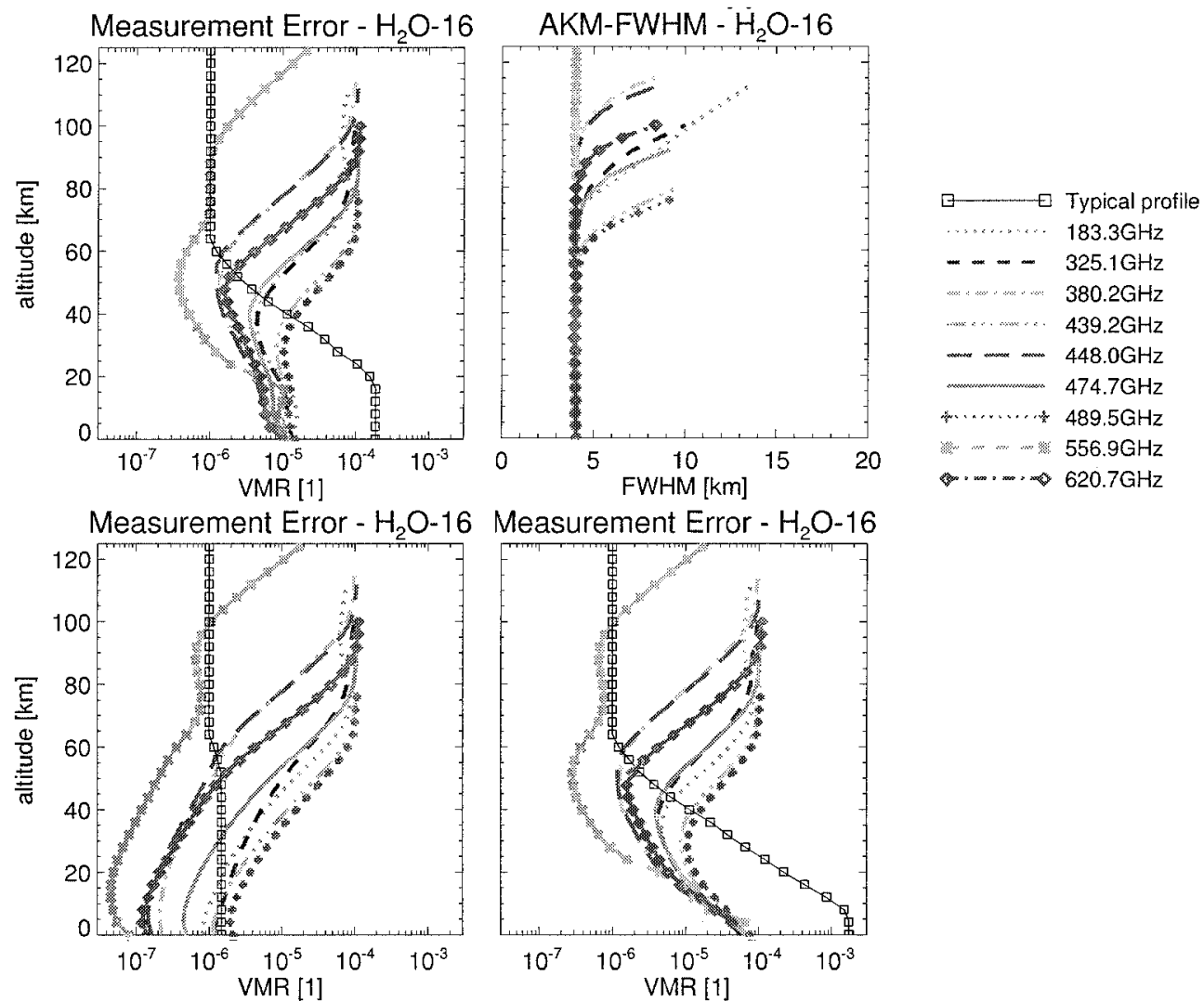

Fig. 13. Top, comparison of measurement precision (left) and altitude resolution (right) for single-scan profile retrievals from $\mathrm{H}_{2} \mathrm{O}$ target lines in the 150-650-GHz range (standard conditions). Bottom, retrieval precision for extremely dry (left) and extremely wet (right) conditions. Typical profiles are given for comparison. 


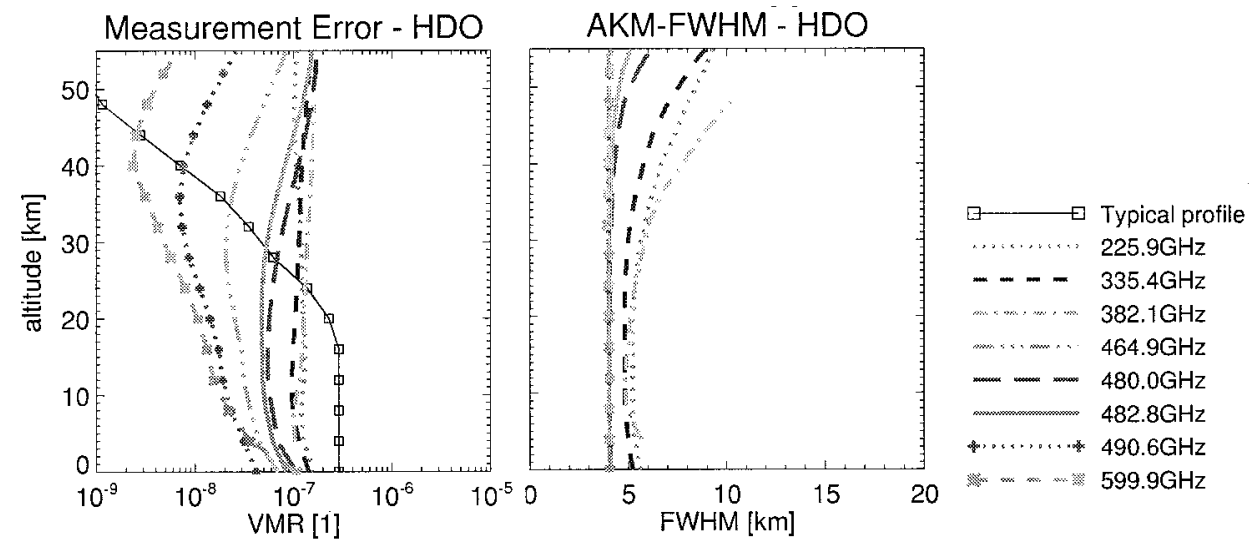

Fig. 14. Comparison of measurement precision (left) and altitude resolution (right) for single-scan profile retrievals from potential HDO target lines in the $150-650-\mathrm{GHz}$ range. A typical profile is shown as well.

extremely wet atmosphere, affected by strong selfabsorption at tangent altitudes below $\sim 10 \mathrm{~km}$. Spectral measurements of the 183.3-, 325.1-, and 474.7-GHz $\mathrm{H}_{2} \mathrm{O}$ lines give similar results and allow single-scan profile information to be retrieved up to roughly $40-45 \mathrm{~km}$ for standard and wet conditions, but data have to be averaged to yield useful information on the extremely dry atmosphere.

The theoretically achievable precision and altitude resolution for the submillimeter wave transitions of HDO under investigation are compared in Fig. 14. Best results were found for the strongest lines at 490.6 and $599.9 \mathrm{GHz}$, allowing useful singleprofile information to be retrieved up to $35-40 \mathrm{~km}$, but self-absorption might here also be a limiting factor at the lowest tangent views below $10 \mathrm{~km}$ in an extremely wet atmosphere. In general, line intensities increase considerably with frequency, leading to an improved retrieval precision and exploitable altitude range for the higher-frequency lines of HDO. This result is also reflected in the measurement precision for the $\mathrm{D} / \mathrm{H}$ ratio, which is shown in Fig. 15 for single-profile retrievals from different $\mathrm{H}_{2} \mathrm{O}$ and $\mathrm{HDO}$ line pairs. The study of isotopic fractionation above the condensation level would cer- tainly benefit if the strongest $\mathrm{H}_{2} \mathrm{O}$ and $\mathrm{HDO}$ lines were measured.

To conclude, given the constraints on the design of a compact and low-mass instrument, the choice of the $435-465-\mathrm{GHz}$ spectral range could represent a reasonable compromise and an alternative to the $320-350 \mathrm{GHz}$ range. Main bands would cover lines of ${ }^{13} \mathrm{CO}$ and ${ }^{12} \mathrm{CO}$ at 440.8 and $461.0 \mathrm{GHz}$, respectively, as well as a strong $\mathrm{H}_{2} \mathrm{O}$ transition at $448.0 \mathrm{GHz}$ and a HDO line at $464.9 \mathrm{GHz}$. Strong transitions of the secondary target species $\mathrm{O}_{3}$ and $\mathrm{H}_{2} \mathrm{O}_{2}$ are available in this range, and $\mathrm{O}_{2}$ lines in the vicinity (424.8 and $487.3 \mathrm{GHz}$ ) could possibly be targeted as well. Simultaneous measurements of a slightly weaker $\mathrm{H}_{2} \mathrm{O}$ line at $439.2 \mathrm{GHz}$ could also help to improve the retrieval at the lowest tangent altitudes. The combination of different frequency ranges in one instrument would theoretically also be an option, for example, with the goal of observing stronger and weaker target lines of a species such as $\mathrm{H}_{2} \mathrm{O}$ to maximize the measurement information at low and high altitudes but certainly at the cost of higher instrument design complexity, weight, and power consumption. Such technical constraints will have to be carefully investigated.

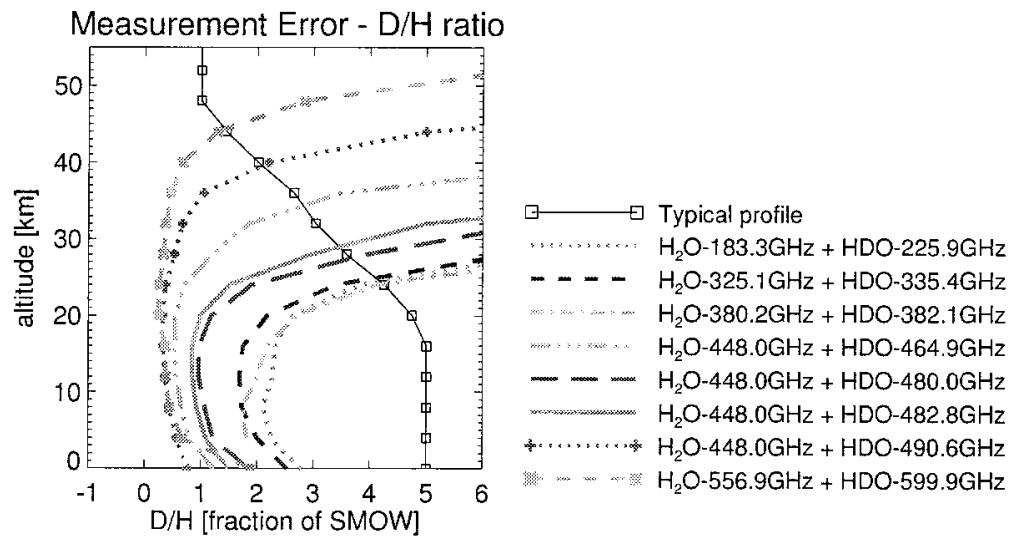

Fig. 15. Comparison of the measurement precision of the $\mathrm{D} / \mathrm{H}$ ratio derived from single-scan profile retrievals from different $\mathrm{H}_{2} \mathrm{O}$ and HDO line pairs in the $150-650-\mathrm{GHz}$ range. The profile of the standard scenario (with $80 \%$ depletion above $45 \mathrm{~km}$ ) is shown for comparison. 


\section{Discussion and Conclusions}

Our investigation of submillimeter-wave heterodyne spectroscopy of the Martian atmosphere, based on a well-defined concept for the instrumentation, clearly demonstrates the feasibility of such measurements and thus confirms and extends conclusions drawn in earlier studies. ${ }^{31,49,50}$ In particular, we have provided quantitative estimates of achievable measurement precisions, altitude ranges, and vertical resolutions for the important parameters $\mathrm{H}_{2} \mathrm{O}, \mathrm{HDO},{ }^{12} \mathrm{CO},{ }^{13} \mathrm{CO}$, temperature, $\mathrm{O}_{3}$, and $\mathrm{H}_{2} \mathrm{O}_{2}$ measured in the $320-350-\mathrm{GHz}$ range with a state-of-the-art satellite receiver on a low Mars orbit.

Temperature is the main parameter that controls physical and chemical processes. Limb observations of lines of ${ }^{12} \mathrm{CO}(345.8 \mathrm{GHz})$ and ${ }^{13} \mathrm{CO}(330.6 \mathrm{GHz})$ would provide vertically well-resolved temperature information on a global scale during all seasons, during day and night, and even under extreme conditions such as dust storms. The altitude range from 0 to $\sim 90 \mathrm{~km}$ covers the range where most of the atmospheric structures persist, and the vertical resolution of the order of one-half scale height allows wave structures such as gravity waves to be resolved. Zonal-mean temperature fields with a reduced altitude resolution of the order of 10-12 km would reach even altitudes of $\sim 120 \mathrm{~km}$.

Moreover, direct measurements of the slowly varying long-lived species ${ }^{12} \mathrm{CO}$ and its isotope ${ }^{13} \mathrm{CO}$ would become available, permitting, for example, slow meridional transport processes to be traced, in addition to direct observations of winds from the Doppler shifts of the simultaneously measured ${ }^{12} \mathrm{CO}$ and ${ }^{13} \mathrm{CO}$ lines. Note that a dedicated study that used a classic least-squares approach has shown that a rms measurement precision of better than $10 \mathrm{~m} / \mathrm{s}$ from 20 to $100 \mathrm{~km}$ can be obtained from the spectral measurements of a single limb scan, ${ }^{6}$ to be compared with wind velocities that can be as high as $150-200 \mathrm{~m} / \mathrm{s}$ in the middle atmosphere of Mars. ${ }^{13}$ Global observations based on a submillimeter-wave limb-sounder concept with dedicated bands in the $320-350-\mathrm{GHz}$ range would thus allow a full description of the dynamics of the Martian atmosphere.

Single-scan limb observations of the $325.2-\mathrm{GHz}$ $\mathrm{H}_{2} \mathrm{O}$ line would allow global water-vapor fields to be measured from 0 to $40-45 \mathrm{~km}$ with unprecedented sensitivity, with half-scale height vertical resolution, and even under extremely wet $\left(\mathrm{H}_{2} \mathrm{O}\right.$ column, $\sim 120 \mathrm{pr}-\mu \mathrm{m})$ and moderately dry $(\sim 3 \mathrm{pr}-\mu \mathrm{m})$ conditions, valuable information for the study of the diurnal, seasonal, and interannual exchange cycles with surface reservoirs such as the polar ice caps and the regolith. Averaging of data would provide information at even higher altitudes or under the extremely dry atmospheric conditions at the winter pole $(\sim 0.15 \mathrm{pr}-\mu \mathrm{m})$, information that would still be useful to constrain chemical-dynamical models of the Martian atmosphere. Simultaneous HDO (335.4 GHz) limb observations would allow information on the $\mathrm{D} / \mathrm{H}$ ratio in the lower Martian atmosphere to be derived up to roughly $30 \mathrm{~km}$, which would be particularly useful for the study of a variety of dynamic processes involving, for example, condensation.

It has been demonstrated that limb sounding provides much better altitude ranges, resolutions, and measurement sensitivities than nadir sounding. Moreover, global fields of photochemically important minor constituents such as $\mathrm{O}_{3}(326.90 \mathrm{GHz})$ and the reservoir for odd hydrogen radicals $\mathrm{H}_{2} \mathrm{O}_{2}(326.98 \mathrm{GHz})$ can be obtained only by use of the much longer emission path of the limb observation geometry.

On the other hand, nadir observations with good horizontal resolution of better than $30 \mathrm{~km}$ along the satellite track, to be compared with the length of the limb emission path of $\sim 330 \mathrm{~km}$ for a 4 -km-thick layer at the tangent point, provide valuable complementary information, for example, on the detection of meteorological phenomena with strong horizontal gradients in temperature and humidity (e.g., weather fronts). Moreover, nadir observations of surface brightness temperatures in two polarizations, performed between limb scans, would permit mapping of surface characteristics on a global scale. Quantities such as the effective emission of the ground and the temperature profile in the lower atmosphere are in turn important for the initialization of nonlinear retrieval of atmospheric parameters from the limb observations.

Compared with the typical observation capabilities of present IR nadir sounders such as the Thermal Emission Spectrometer ${ }^{9}$ (TES) of the Mars Global Surveyor (MGS) mission or the Planetary FourierTransform Spectrometer ${ }^{19}$ (PFS) on Mars Express, a submillimeter-wave limb-sounder approach would provide a considerably better altitude coverage for temperature, profile measurements instead of total columns for $\mathrm{H}_{2} \mathrm{O}$ and $\mathrm{HDO}$, as well as profile measurements of ${ }^{12} \mathrm{CO},{ }^{13} \mathrm{CO}, \mathrm{O}_{3}$, and $\mathrm{H}_{2} \mathrm{O}_{2}$. Compared with solar and stellar limb occultation techniques such as those employed by SPICAM (Spectroscopy for the Investigation of the Characteristics of the Atmosphere of Mars ${ }^{18}$ ) on Mars Express, capable of providing, for example, accurate profile measurements of $\mathrm{H}_{2} \mathrm{O}$ and $\mathrm{O}_{3}$, a major advantage of the concept investigated here is the much better temporal and global coverage of thermal emission measurements. The relative insensitivity to aerosols compared with UVvisible and IR techniques, as well as the validity of the LTE assumption even at high altitudes (in contrast to the thermal IR range), should also be recalled as general advantages of submillimeter-wave emission sounding.

Besides conducting a detailed investigation of the observation capabilities of a state-of-the-art limb sounder in the $320-350-\mathrm{GHz}$ range, we also explored alternative frequency band selections and estimated retrieval precisions for the most important target lines of $\mathrm{H}_{2} \mathrm{O}, \mathrm{HDO},{ }^{12} \mathrm{CO}$, and ${ }^{13} \mathrm{CO}$ in the $150-650-\mathrm{GHz}$ range. For the design of a compact het- 
erodyne receiver the $435-465-\mathrm{GHz}$ spectral range represents a possible alternative that would allow somewhat stronger transitions of the key target species ${ }^{12} \mathrm{CO},{ }^{13} \mathrm{CO}, \mathrm{H}_{2} \mathrm{O}$, and HDO to be observed. However, the technical feasibility of such an instrument would need to be analyzed in a more dedicated study, given the typically stringent requirements on dimensions, mass, and power consumption for spaceborne instrumentation. Complementarity with other instruments on the same platform would also be an important criterion for the target line selection of a future submillimeter limb sounder for the investigation of the Martian atmosphere.

We thank our numerous colleagues of the international (French, American, German, Swedish) MAMBO team, including G. Beaudin, A. Deschamps, P. Encrenaz, M. Gheudin, B. Thomas, M. Capderou, M. Frerking, S. Gulkis, M. Janssen, L. Riley, T. Encrenaz, E. Lellouch, P. Hartogh, and T. Clancy, for motivation and excellent collaboration during phase A of the project. Thanks are also due to Françoise Billebaud for critical comments on the manuscript. The study presented here was funded by grants from the Centre National d'Études Spatiales in France.

\section{References and Notes}

1. R. M. Haberle, J. B. Pollack, J. R. Barnes, R. W. Zurek, C. B. Leovy, J. R. Murphy, H. Lee, and J. Schaeffer, "Mars atmospheric dynamics as simulated by the NASA AMES General Circulation Model. I. The zonal-mean circulation," J. Geophys. Res. 98, 3093-3123 (1993).

2. R. Wilson and K. Hamilton, "Comprehensive model simulation of thermal tides in the Martian atmosphere," J. Atmos. Sci. 53, 1290-1326 (1996).

3. F. Forget, F. Hourdin, R. Fournier, C. Hourdin, O. Talagrand, M. Collins, S. Louis, P. Read, and J.-P. Huot, "An improved general circulation model of the Martian atmosphere from the surface to above $80 \mathrm{~km}$," J. Geophys. Res. 104, 24,155-24,176 (1999).

4. B. M. Jakosky and R. J. Phillips, "Mars volatile and climate history," Nature 412, 237-244 (2001).

5. C. Leovy, "Weather and climate on Mars," Nature 412, 245249 (2001)

6. F. Forget, K. Dassas, M. Capderou, S. Lebonnois, G. Beaudin, A. Deschamps, P. Encrenaz, B. Germain, M. Gheudin, A. Maestrini, C. Prigent, B. Thomas, P. Ricaud, J. Urban, M. Janssen, M. Frerking, S. Gulkis, L. Riley, M. Allen, T. Encrenaz, E. Lellouch, P. Hartogh, R. Clancy, E. Chassefiere, F. Lefèvre, F. Montmessin, A. Emrich, D. Murtagh, R. Booth, U. Frisk, and A. Raisanen, "Mars atmosphere microwave brightness observer," Tech. Rep. (Laboratoire de Météorologie Dynamique, IPSL, Université de Pierre et Marie Curie, Paris (May 2002).

7. V. A. Krasnopolsky, "Mars photochemistry: weak points and search for solutions," in Sixth International Conference on Mars (Lunar and Planetary Institute, Houston, Texas, 2003), pp. 3002-3004; http://www.lpi.usra.edu/meetings/ sixthmars2003/abstractvolume.html.

8. A. L. Albee, R. E. Arvidson, F. Palluconi, and T. Thorpe, "Overview of the Mars Global Surveyor mission," J. Geophys. Res. 106, 23291-23316 (2001).

9. P. R. Christensen, D. L. Anderson, S. C. Chase, R. T. Clancy, R. N. Clark, B. J. Conrath, H. H. Kieffer, R. O. Kuzmin, M. C. Malin, J. C. Pearl, T. L. Roush, and M. D. Smith, "Results from the Mars Global Surveyor Thermal Emission Spectrometer," Science 279, 1692-1698 (1998).
10. B. J. Conrath, J. C. Pearl, M. D. Smith, W. C. Maguire, P. R. Christensen, S. Dason, and M. S. Kaelberer, "Mars Global Surveyor Thermal Emission Spectrometer (TES) observations: atmospheric temperatures during aerobraking and science phasing," J. Geophys. Res. 105, 9509-9520 (2000).

11. R. T. Clancy, B. J. Sandor, M. J. Wolff, P. R. Christensen, M. D. Smith, J. C. Pearl, B. J. Conrath, and R. J. Wilson, "An intercomparison of ground-based millimeter, MGS TES, and Viking atmospheric temperature measurements: seasonal and interannual variability of temperatures and dust loading in the global Mars atmosphere," J. Geophys. Res. 105, 9553-9572 (2000).

12. M. Smith, J. Pearl, C. Conrath, and P. Christensen, "Thermal Emission Spectrometer results: Mars atmospheric thermal structure and aerosol distribution," J. Geophys. Res. 106, 23,929-23,945 (2001).

13. E. Lellouch, J. Rosenqvist, J. J. Goldstein, S. W. Bougher, and G. Paubert, "First absolute wind measurements in the middle atmosphere of Mars," Astrophys. J. 383, 401-406 (1991).

14. M. Smith, "The annual cycle of water vapor on Mars as observed by the Thermal Emission Spectrometer," J. Geophys. Res. 107, 25-1-25-19 (2002).

15. T. Encrenaz, E. Lellouch, G. Paubert, and S. Gulkis, "The water vapor vertical distribution on Mars from millimeter transitions of $\mathrm{HDO}$ and $\mathrm{H}_{2} \mathrm{O}$," Planet. Space Sci. 49, 731-741 (2001).

16. M. J. Mumma, R. E. Novak, M. A. Disanti, B. Bonev, N. dello Russo, and K. Magee-Sauer, "Seasonal Mapping of HDO and $\mathrm{H}_{2} \mathrm{O}$ in the Martian atmosphere," in Sixth International Conference on Mars (Lunar and Planetary Institute, Houston, Texas, 2003), pp. 3186-3188; http://www.lpi.usra.edu/ meetings/sixthmars2003/abstractvolume.html.

17. A. F. Chicarro and the Science Team, "The Mars Express mission and its Beagle-2 lander," in Sixth International Conference on Mars (Lunar and Planetary Institute, Houston, Texas,2003),pp.3049-3051;http://www.lpi.usra.edu/meetings/ sixthmars2003/abstractvolume.html.

18. J.-L. Bertaux, D. Fonteyn, O. Korablev, E. Chassefière, E. Dimarellis, J. Dubois, A. Hauchecorne, M. Cabane, P. Rannou, A. Levasseur-Regourd, G. Cernogora, E. Quemerais, C. Hermans, G. Kockarts, C. Lippens, M. Maziere, D. Moreau, C. Muller, B. Neefs, P. Simon, F. Forget, F. Hourdin, O. Talagrand, V. Moroz, A. Rodin, B. Sandel, and A. Stern, "The study of the Martian atmosphere from top to bottom with SPICAM light on Mars Express," Planet. Space Sci. 48, 1303-1320 (2000).

19. V. Formisano, D. Grassi, N. Ignatiev, L. Zasova, and A. Maturilli, "PFS for Mars Express: a new approach to study Martian atmosphere," Adv. Space Res. 29, 131-142 (2002).

20. http://mars.jpl.nasa.gov/mro/mission/.

21. S. Bühler, A. von Engeln, J. Urban, J. Wohlgemuth, and K. Künzi, "Investigation of sensitivity to cloud," in Study on Upper Troposphere/Lower Stratosphere Sounding, ESA/ESTEC, 1999, W. J. Reburn, ed., ESTEC contract 12053/97/NL/CN (European Space Research and Technology Centre, Noordwijk, The Netherlands, 1999), pp. 435-569.

22. C. Emde, S. Buehler, P. Eriksson, and T. Sreerekha, "The effect of cirrus clouds on microwave limb radiances," J. Atmos. Res. 72(1-4) 383-401 (2004), doi: 10.1016/j.atmosres. 2004.03.023.

23. M. Wolff and R. Clancy, "Constraints on the Size of Martian Aerosols from TES spectral observation," J. Geophys. Res. 108(E9) 1-1-1-23 (2003), doi: 10.1029/2003JE002057.

24. R. Clancy, M. Wolff, and P. Christensen, "Mars Aerosol Studies with the MGS TES emission phase function observations: optical depths, particle sizes, and ice cloud types versus latitude and solar longitude," J. Geophys. Res. 108(E9) 2-1-2-20 (2003), doi: 10.1029/2003JE002058. 
25. M. A. Lopez-Valverde and M. Lopez-Puertas, "A non-local thermodynamic equilibrium radiative transfer model for infrared emissions in the atmosphere of Mars. 1. Theoretical basis and nighttime populations of vibrational levels," J. Geophys. Res. 99, 13,093-13,115 (1994).

26. J. E. Waters, "An overview of the EOS MLS experiment," Tech. Rep. JPL D-15745 (Jet Propulsion Laboratory, Pasadena, Calif., 1999), http://mls.jpl.nasa.gov/ (January 15 1999).

27. G. Melnick, J. Stauffer, M. Ashby, E. Bergin, G. Chin, N. Erickson, P. Goldsmith, M. Harwit, J. Howe, S. Kleiner, D. Koch, D. Neufeld, B. Patten, R. Plume, R. Schieder, R. Snell, V. Tolls, Z. Wang, G. Winnewisser, and Y. Zhang, "The Submillimeter Wave Astronomy Satellite: science objectives and instrument description,” Astrophys. J. 539, L77-L85 (2000).

28. U. Frisk, M. Hagström, J. Ala-Laurinaho, S. Andersson, J.-C. Berges, J.-P. Chabaud, M. Dahlgren, A. Emrich, H.-G. Florén, G. Florin, M. Fredrixon, T. Gaier, R. Haas, T. Hirvonen, A. Hjalmarsson, B. Jakobsson, P. Jukkala, P. Kildal, E. Kollberg, J. Lassing, A. Lecacheux, P. Lehikoinen, A. Lehto, J. Mallat, C. Marty, D. Michet, J. Narbonne, M. Nexon, M. Olberg, O. Olofsson, G. Olofsson, A. Origné, M. Petersson, P. Piironen, R. Pons, D. Pouliquen, I. Ristocelli, C. Rosolen, G. Rouaix, A. Räisänen, G. Serra, F. Sjöberg, L. Stenmark, S. Torchinsky, J. Tuovinen, C. Ullberg, E. Vinterhav, N. Wadefalk, H. Zirath, P. Zimmermann, and R. Zimmermann, "The Odin satellite. I. Radiometer design and test," Astron. Astrophys. 402, L27-L34 (2003).

29. T. Owen, J. P. Maillard, C. de Bergh, and B. L. Lutz, "Deuterium on Mars - the abundance of $\mathrm{HDO}$ and the value of $\mathrm{D} / \mathrm{H}$," Science 240, 1767-1770 (1988).

30. V. A. Krasnopolsky, G. L. Bjoraker, M. J. Mumma, and D. E. Jennings, "High-resolution spectroscopy of Mars at 3.7 and $8 \mu \mathrm{m}$ : a sensitive search of $\mathrm{H}_{2} \mathrm{O}_{2}, \mathrm{H}_{2} \mathrm{CO}, \mathrm{HCl}$, and $\mathrm{CH}_{4}$, and detection of HDO," J. Geophys. Res. 102, 6525-6534 (1997).

31. T. Fouchet and E. Lellouch, "Vapor pressure isotope fractionation effects in planetary atmospheres: application to deuterium," Icarus 144, 114-123 (2000).

32. J. Bertaux and F. Montmessin, "Isotopic fractionation through water vapor condensation: the deuteropause, a cold trap for deuterium in the atmosphere of Mars," J. Geophys. Res. 106, 32,879-32,884 (2001).

33. E. Lellouch, G. Paubert, and T. Encrenaz, "Mapping of CO millimeter-wave lines in Mars' atmosphere-the spatial variability of carbon monoxide on Mars," Planet. Space Sci. 39, 219-224 (1991).

34. M. McElroy and J. Mcdonnell, "Dissociation of $\mathrm{CO}_{2}$ in the Martian atmosphere," J. Atmos. Sci. 28, 879-884 (1972).

35. M. A. Bullock, C. R. Stoker, C. P. McKay, and A. P. Zent, "A coupled soil-atmosphere model of $\mathrm{H}_{2} \mathrm{O}_{2}$ on Mars," Icarus 107, 142-154 (1994).

36. R. T. Clancy and H. Nair, "Annual (perihelion-aphelion) cycles in the photochemical behavior of the global Mars atmosphere," J. Geophys. Res. 101, 12,785-12,790 (1996).

37. J. Urban and D. Lamarre, "Investigation of instrumental parameters," in The Retrieval of Data from Sub-Millimetre Limb Sounding - CCN 2, ESTEC contract 11979/97/NL/CN-CCN2,
(European Space Research and Technology Centre, Noordwijk, The Netherlands, 2000), Chap. 3, pp. 149-209.

38. J. Urban, P. Baron, N. Lautié, K. Dassas, N. Schneider, P. Ricaud, and J. de La Noë, "MOLIERE (v5): a versatile forwardand inversion model for the millimeter and sub-millimeter wavelength range," J. Quant. Spectrosc. Radiat. Transfer 83, 529-554 (2004).

39. C. Melsheimer, C. Verdes, S. Buehler, C. Emde, P. Eriksson, D. Feist, S. Ichizawa, V. John, Y. Kasai, G. Kopp, N. Koulev, T. Kuhn, O. Lemke, S. Ochiai, F. Schreier, T. Sreerekha, M. Suzuki, C. Takahashi, S. Tsujimaru, and J. Urban, "Intercomparison of general purpose clear-sky atmospheric radiative transfer models for the millimeter/sub-millimeter spectral range," Radio Sci. 40, R51007, doi: 10.1029/2004RS003110 (2005).

40. S. Clough, F. Kneizys, and R. Davies, "Line shape and the water vapor continuum," Atmos. Res. 23, 229-241 (1989).

41. P. Rosenkranz, "Absorption of microwaves by atmospheric gases," in Atmospheric Remote Sensing by Microwave Radiometry, M. A. Janssen, ed., Wiley Series in Remote Sensing (Wiley, New York, 1993), Chap. 2, pp. 37-82.

42. C. D. Rodgers, "Retrieval of atmospheric temperature and composition from remote measurements of thermal radiation," Rev. Geophys. Space Phys. 14, 609-624 (1976).

43. P. Eriksson, "Microwave radiometric observations of the middle atmosphere: simulations and inversions," Ph.D. dissertation (Chalmers University of Technology, Göteburg, Sweden, 1999)

44. http://www.rss.chalmers.se/gem/research/verdandi.html.

45. H. Pickett, R. Poynter, E. Cohen, M. Delitsky, J. Pearson, and H. Müller, "Submillimeter, millimeter, and microwave spectral line catalog," J. Quant. Spectrosc. Radiat. Transfer 60, 883-890 (1998).

46. L. Rothman, A. Barbe, D. Benner, L. Brown, C. Camy-Peyret, M. Carleer, K. Chance, C. Clerbaux, V. Dana, V. Devi, A. Fayr, J.-M. Flaud, R. Gamache, A. Goldman, D. Jaquemart, K. Jucks, W. Lafferty, J.-Y. Mandin, S. Massie, V. Nemtchinov, D. Newnham, A. Perrin, C. Rinsland, J. Schroeder, K. Smith, M. Smith, K. Tang, R. Toth, J. Vander Auwera, P. Varanasi, and K. Yoshino, "The HITRAN Molecular Spectroscopic Database: edition of 2000 including updates through 2001," J. Quant. Spectrosc. Radiat. Transfer 82, 5-44 (2003).

47. D. Priem, F. Rohart, J.-M. Colmont, G. Wlodarcsak, and J. Bouanich, "Lineshape study of the $J=3-2$ rotational transition of CO perturbed by $\mathrm{N}_{2}$ and $\mathrm{O}_{2}$," J. Mol. Struct. 517-518 435-454 (2000)

48. P. Varanasi and J. Tegwani, "Half width calculations for CO lines broadened by $\mathrm{CO}_{2}$," J. Quant. Spectrosc. Radiat. Transfer 11, 255-261 (1971).

49. D. Muhleman and R. Clancy, "Microwave spectroscopy of the Mars atmosphere," Appl. Opt. 34, 6067-6080 (1995).

50. T. Encrenaz, A. Coradini, G. Beaudin, J. Crovisier, P. Drossart, S. Erard, B. Germain, S. Gulkis, Y. Langevin, and E. Lellouch, "The Mars flyby of ROSETTA: an opportunity for infrared and microwave high-resolution sounding," Planet. Space Sci. 49, 673-687 (2001). 